\title{
Geothermal Permeability Enhancement Final Report
}

\section{Table of Contents}

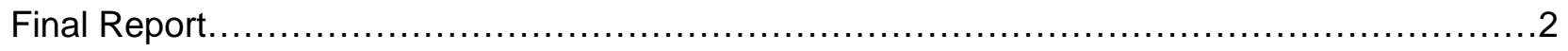

Appendix 1 .

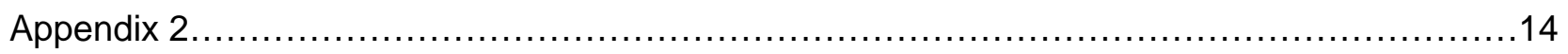

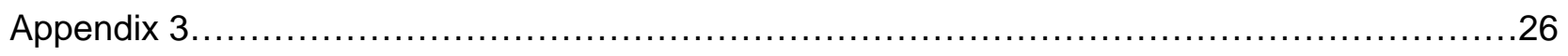

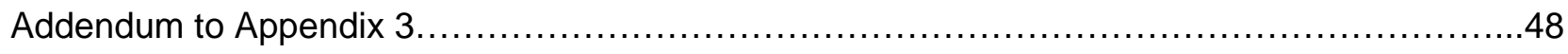




\section{FINAL REPORT}

Project Title: $\quad$ Geothermal Permeability Enhancement

Date of Report: June 30, 2009

Recipient: $\quad$ Calpine Corporation 10350 Socrates Mine Road

Middletown, CA, 95461

Award Number: $\quad$ DE-FC36-02ID14405; Amendment No. M006

Contact(s): $\quad$ Principal Investigator: Joe Beall 10350 Socrates Mine Road, Middletown, CA 95461

(707) 431-6101 joe@calpine.com

Project Manager: Mark Walters 10350 Socrates Mine Road, Middletown, CA 95461 (707) 431-6101 waltersm@calpine.com

Project Team: $\quad$ DOE Project Manager: Eric K. Hass

National Renewable Energy Laboratory

1617 Cole Boulevard, Golden, CO 80401-3393

DOE Contracting Officer: Genevieve Wozniak

US DOE Golden Field Office

1617 Cole Boulevard, Golden, CO 80401-3393

DOE Grants and Agreement Specialist: Pete Simon

US DOE Golden Field Office

1617 Cole Boulevard, Golden, CO 80401-3393

Project Objective: The overall objective is to apply known permeability enhancement techniques to reduce the number of wells needed and demonstrate the applicability of the techniques to other undeveloped or under-developed fields.

The Enhanced Geothermal System (EGS) concept presented in this project enhances energy extraction from reduced permeability zones in the super heated, vapor dominated Aidlin Field of The Geysers geothermal reservoir.

Numerous geothermal reservoirs worldwide, over a wide temperature range, contain zones of low permeability which limit the development potential and the efficient recovery of heat from these reservoirs. Low 

fractures.

The Enhanced Geothermal System concept presented here is expands these technologies by applying and evaluating them in a systematic, integrated program.

Background: $\quad$ At Calpine's Geysers field, zones of high temperature and corrosive steam are found in rocks having poor permeability. Successful enhancement of permeability will improve the economic viability of these currently underdeveloped resources, and encourage development of other high temperature, low-permeability resources elsewhere.

The passive injection of water into high temperature rocks has the benefit of increasing permeability and saturation of reservoir rock, and lowering of non-condensable gas concentrations in produced steam.

The high temperatures found in the vapor dominated, super heated Geysers reservoir is a challenge to logging and sampling tools such as downhole geochemical samplers and pressure-temperature-spinner tools needed to evaluate high temperature reservoirs with low permeability.

High temperature reservoir steam contains potentially corrosive concentrations of hydrogen chloride gas that must be mitigated prior to reaching pipelines, separators, or power plants.

Calpine developed a systematic and integrated program to address the problems of poor permeability in high temperature rocks with an EGS injection project at the Aidlin steamfield, collaborated in the deployment of a high temperature downhole sampler (DHS), and constructed a dry steam separator (DSS) to remove corrosive chloride at the wellhead.

Work associated with this project included an injection pipeline and the addition of micro-seismic monitoring stations to the Lawrence Berkeley National Laboratory (LBLN) seismic array in the area of the Aidlin steamfield.

\section{Status:}

\section{Aidlin-11 EGS Injection Project}

The Santa Rosa Geysers Recharge Pipeline (SRGRP) to the Aidlin 11 well was operational in November 2005, and since than has received an average of 0.4 million gallons per day. The pipeline represents the northernmost extension of the SRGRP Project. Aidlin 11 remains the only injection well within the Aidlin project at this date.

Currently the benefits of injection at Aidlin-11 are approximately $2.5 \mathrm{MW}$ of new generation from reservoir enhancement. 
DE-FC07-02ID14405; Amendment No. M006

Six additional micro-seismic monitoring stations around the Aidlin steamfield were installed. The LBNL network began recording data in April 2003, and has been operational since 14 October 2003. The final report on the project (Lawrence Berkeley National Laboratory et al., 2004) is available from the California Energy Commission. By the end of 2004, the data flow had been integrated into the Northern California Seismic Network (NCSN) system, providing public access to the data via the Internet. In effect, the data from the LBNL stations are incorporated into the NCSN dataset. The integrated NCSN/LBNL dataset appears to be reliably recording earthquakes down to M 1.0.

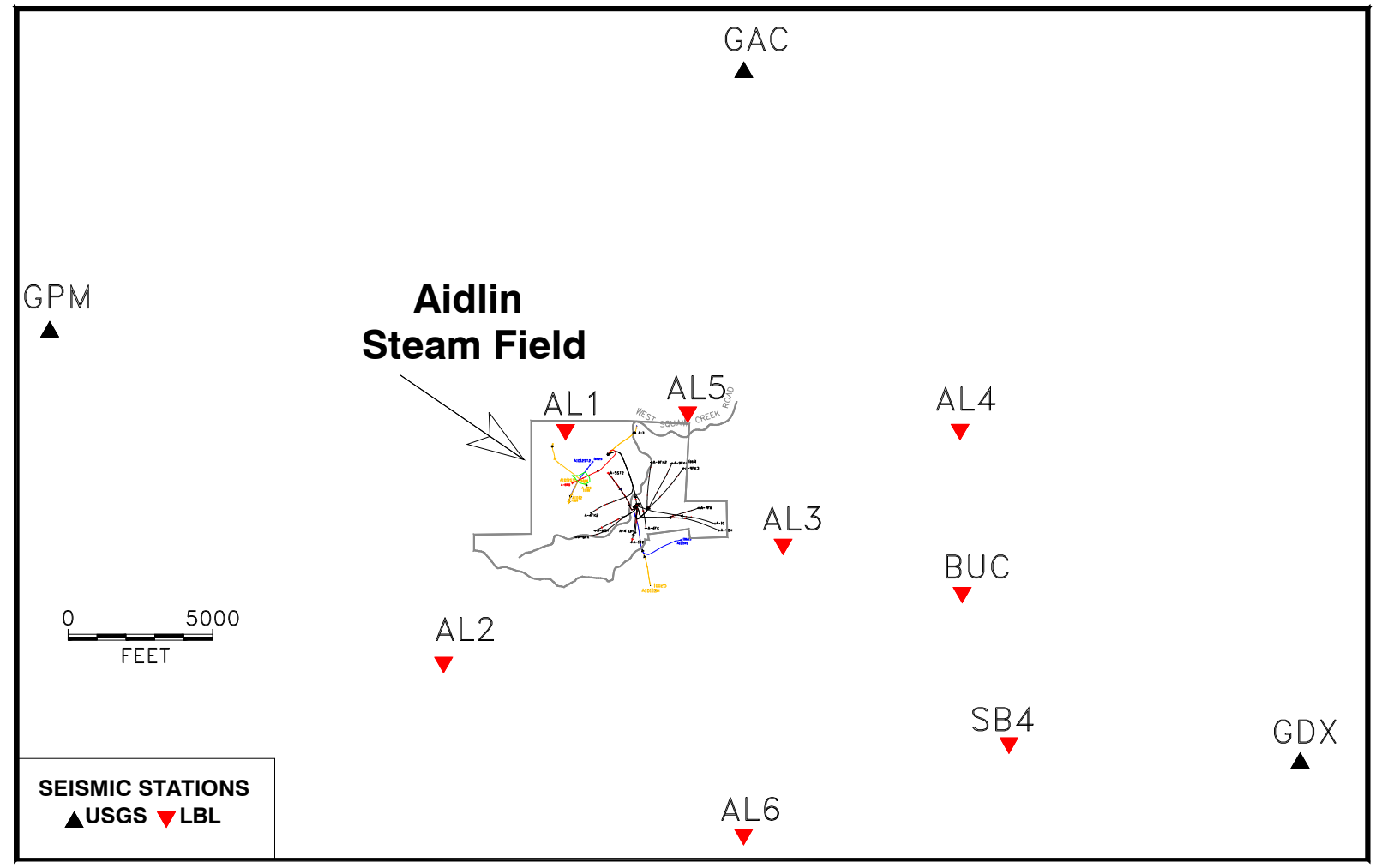

Figure 1. Aidlin steam field and surrounding seismic stations.

Regular geochemical monitoring of the noncondensible gas fractions of steam in the Aidlin steamfield production wells show significant to large decreases in NCG concentration in wells affected by injection into Aidlin 11.

A 300 Curie tritium tracer test began on May 5, 2008 at The Geysers. Aidlin 11 injection well received a proportional dose of this tracer. The injected Santa Rosa recharge water from Aidlin 11 was traced to adjacent steam production wells. The tracer data indicate those wells which producing the greatest share of injection-derived steam from Aidlin 11 also have the largest lowered noncondensible gas concentrations. The slow return of tracer from the Aidlin 11 injection wells confirms production testing data that the permeability of the Aidlin steam field is about an order of magnitude less than the greater part of the Geysers steamfield. 
Interpretation of the tracer test data along with geochemical monitoring are included in Appendix 1 as Final Aidlin-11 Data Analysis and Report, June 9, 2009.. This report highlights the effects of injection on steam chemistry and illustrates the use of tritium tracer in injected water to map the movement of injection-derived steam in the reservoir.

\section{Seismicity Educational Exhibit}

Calpine installed an educational exhibit on earthquakes at the Geysers Visitor Center to address public concerns about induced seismicity associated with EGS projects. The centerpieces of the exhibit are two operating seismic recorders; one transmitting data from a sensor in the steam field, and the other from a sensor located in the Visitor Center Building, so visitors can "make their own earthquake." The recorders were installed and were operational in late December 2007.

\section{Dry Steam Scrubber (DSS)}

The Dry Steam Scrubber is a prototype, full-size DSS vessel built by Calpine from a horizontal separator vessel. Calpine brought the DSS on-line on July 14, 2008 at the Abril2 well. ThermoChem provided laboratory testing and wrote a "washdown" procedure for regenerating the performance of the DSS.

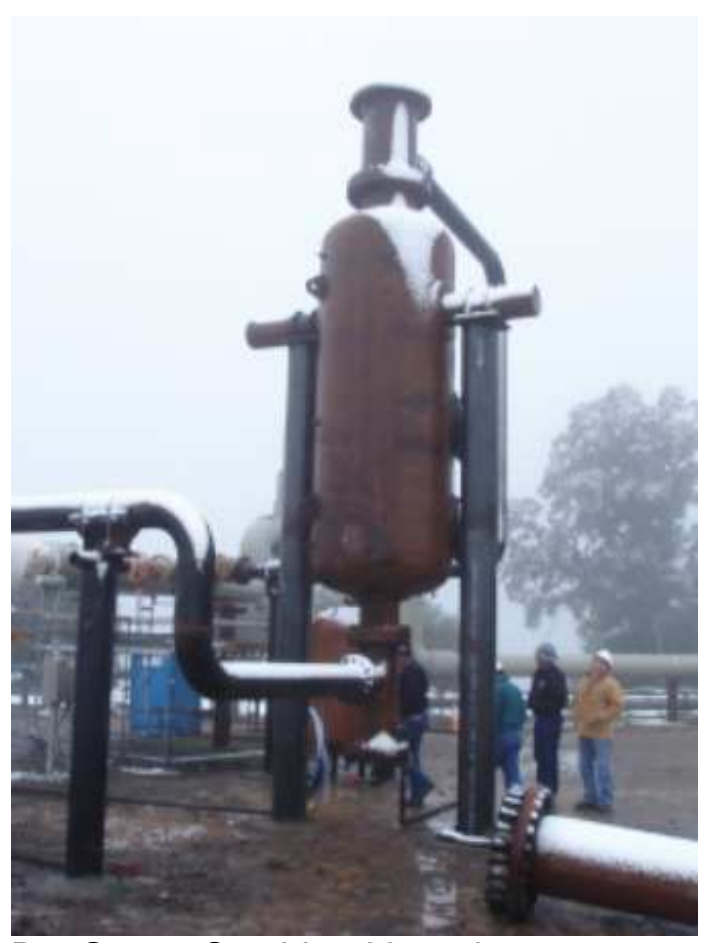

Dry Steam Scrubber Vessel 
The initial flow rate through the DSS vessel was about $40 \mathrm{KPH}$ (forty thousand, or "kilo", pounds per hour), and $30 \mathrm{kph}$ flowing through the main steam pipeline. Samples of the steam from the DSS were collected by ThermoChem. The chloride removal efficiency was determined to be between 92 and $93 \%$ for the duration of the 22 day test.

The pressure drop remained at about 2 psig during the course of the test, reaching a maximum of 2.9 psig before the Abril-2 well was shut-in because of mechanical problems unrelated to the DSS. About $4 \mathrm{degF}$ superheat was lost through the vessel, due to inadequate insulation. The performance of the DSS over 22 days showed no decline in efficiency, and exceeded ThermoChem's theoretical estimates.

A Pilot Test Washdown procedure was written by ThermoChem to regenerate the calcite within the DSS. The purpose of the washdown is to regenerate the calcite within the DSS which is partially reduced by $\mathrm{HCl}$ to highly soluble calcium chloride. The calcium chloride byproduct is highly soluble in water. The solids found at the bottom of the DSS vessel following the pilot testing vessel were primarily corrosion products from the well, not the wash process. Washing the bed should not be confused with re-filling the bed with calcite. The bed does not have to be re-filled after every wash.

The pilot test washdown procedure was not completed because of unrelated wellhead separator problems discovered on August 8, 2009 during preparation for the Pilot Test Washdown. There was not insufficient run time to determine the required washdown frequency, but from the performance over 22 days with no significant decline in efficiency, it appears the DSS might have run for 30 days or more between washes.

Operation of the Abril-2 well was later suspended on September 4, 2008 for reasons that included repair of the wellhead separator, and remains suspended due to the high concentration of NCG which compromised the operation of Geysers Unit 11. At this time, Abril 2 will not be returned to service until the non-condensible gas concentrations can be lowered through the injection of water into OF27A-2. The conversion of OF27A-2 to an injection well is presently anticipated in early 2010 .

Abril-2 represents the extreme upper end for corrosive steam to be treated by this process, as it is one of the highest $\mathrm{HCl}$-producing wells in the history of The Geysers. The bulk of the corrosive wells at The Geysers would consume between 3 to 10 times less calcite than Abril 2, resulting in a much lower frequency for washing of the calcite bed and re-fill cycles.

The operational design of the DSS is less than ideal, including the flange sizes and rating, height above the ground, etc. but the intent of the project was to gain experience on the chemical process of removing chloride from steam, not the mechanical process. Therefore the prototype vessel for operational "proof of concept" was a success.

A summary of the evolution and testing/evaluation of the full size DSS prototype is presented in the "Final Report, Full-Scale Dry Steam Scrubbing Test, Abril-2", attached as Appendix 2.

\section{Downhole Sampler (DHS)}


Calpine received DOE funds to build and deploy the Downhole Sampler (DHS) for the sampling of a dry steam reservoir. The funds were passed through to Thermochem by Calpine, for the tool fabrication necessary to adapt a two-phase version of the DHS for use in the corrosive, high temperature, dry steam environment at The Geysers.

Thermochem independently developed the two-phase version of the DHS. Their design includes a eutectic pre-cooler located before the sample chamber which provides a greater heat capacity and larger sample volume compared to previous downhole sampler designs. This version of the tool was successfully deployed several times in The Philippines during 2004 and early 2005 under two-phase well bore conditions.

In order to better accommodate the capture and analysis of corrosive gasses $\left(\mathrm{H}_{2} \mathrm{~S}, \mathrm{HCl}\right)$, trace metals, and low-ph fluids as found at the Geysers, a new downhole geochemical sampling tool was designed with a titanium flow path, cooler, and sample chamber. A longer heat shield was designed to house the new, larger components. More robust solenoid valves were designed and bench-tested. The sub-assembly was re-designed to allow both external pressure and temperature measurement with sample collection at the same time. The upgraded DHS, without the latest computer upgrade was later run in twophase wells at Puna, Hawaii and Salak, Indonesia. A new computer designed to allow for additional data channels and better resolution for both pressure-temperature logging capabilities and sample heat content measurement.

These upgrades were partially funded by the subject DOE grant through Calpine. The grant money was used to help cover the cost of engineering design, hardware for the titanium eutectic cooler, sample chambers, a new heat shield, solenoid valves, instrumentation and part of the prototype computer.

A new prototype computer was received in November of 2008 from Sandia National Laboratory (privately contracted by ThermoChem) and deployed with the DHS at The Geysers in February 2009.

Calpine selected seven candidate Geysers wells in which to run temperature-pressure-spinner surveys, two of which have been sampled using the Downhole Sampler (DHS) developed by Thermochem and Sandia National Laboratory

The criteria used to pick the wells for logging and downhole samplings were:

- Wells with high chloride (suggesting high temperature and a potential EGS reservoir)

- Wells with deep, shallow and intermediate depth steam in order to discriminate between fluids from different vertical intervals.

- Wells with small departure (i.e. low deviation angles from vertical). The closer to vertical, the higher the probability of successfully logging into the deep steam zone. 
The DHS was run the wells listed below, after an initial dummy-tool run with a sinker bar, and pressure-temperature-spinner (PTS) log were completed in each well. The dummy-tool was used to identify any potential mechanical problems in the wellbores that might prevent running to the target depth and/or risk safe retrieval of the PTS and DHS tools.

Wells GDC 11 and GDCF 63A-29 were determined to be clear and safe to run the tools based on dummy runs. Following the successful PTS logging of each of these wells, the DHS tool was deployed in them between February 11 and 17, 2009 at the following depths:

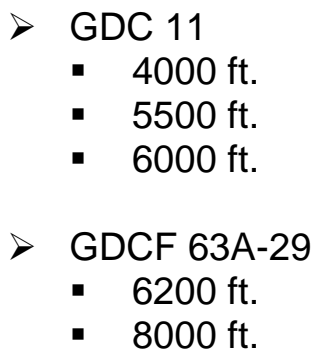

The DHS tool successfully collected samples of steam condensate and noncondensable gas at each targeted depth.

A split of the noncondensible gas (NCG) samples retrieved from GDC 11 and GDCF63A-29by the DHS were made by ThermoChem and provided to Mack Kennedy of LBLN for noble gas isotope analysis. The remaining NCG was analyzed by Thermochem for routine gas analysis. The analyses of the noble gas isotopes, including argon, helium, niobium, krypton, and xenon were completed by LBLN.

The condensate samples were also split with LBLN for chloride isotope chemistry and the remainder analyzed by Thermochem for chloride, boron, sodium and $\mathrm{pH}$.

The raw chemical data, analytical reports, tool design, chemical results integrated with the (PTS) data and a geochemical interpretation are presented in Appendix 3 and an addendum thereto.

Patents:

No patents have been applied for related to this project.

Final Accounting: To be forwarded under separate cover 


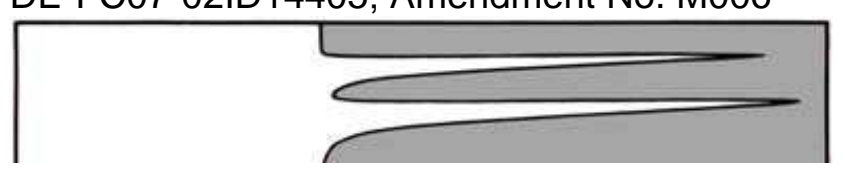

\section{Appendix 1}

Final Aidlin-11 Data Analysis and Report, June 9, 2009 DE-FC36-02ID14405

\section{Introduction}

Aidlin-11 has functioned as the primary injection well for the Aidlin field since 2004. For a time (January 2006 through May 2007), Aidlin-5 was also in service as an injector, but had to be shutin due to breakthrough to a nearby producer. In the last quarterly progress report, it was stated that if Aidlin-5 was able to be brought back into service, Aidlin-11 could be production tested. However, all attempts to regain Aidlin-5 as an injector have failed and therefore no production testing of Aidlin-11 is planned. In November 2007 it was discovered that Aidlin-11's liner was damaged and that the injectivity of the well had dramatically decreased. In anticipation of Aidlin11's failure, a replacement injection well for Aidlin was planned and is presently being drilled and completed. Even though Aidlin-11 has had a limited operational life, measureable benefits have been realized from more than 5 years of injection service.

\section{Aidlin-11 Injection History}

Figure 1 is graph illustrating the monthly injection of Aidlin-11 (shown in the dashed peachcolored line). Also shown is the total Aidlin injection in dark blue. It is apparent that Aidlin-11 has been the dominate injector since early 2004; Aidlin-5 was in service for short time from early 2006 to 2007 . In late 2005 injection at Aidlin increased dramatically. This is when the Santa Rosa Geysers Recharge Pipeline (SRGRP) was extended from the main Geysers field out to Aidlin and allowed additional water to be injected into the reservoir. From late 2005 to early 2008 injection rates at Aidlin were at all time highs. The significant drop off of injection in early 2008 was due to the liner failure in Aidlin-11; as a consequence injection rates were cut back due to water breakthrough to the nearby production well Aidin-7.

\section{Effects of Aidlin-11 Injection \\ NCG concentrations}

Also plotted in Figure 1 are the non condensable gas (NCG) concentrations for each Aidlin production well. Changes in the NCG concentrations of some of the Aidlin production wells can be seen in response to the increase of Aidlin-11 injection in late 2005. It is apparent that Aidlin-1, Aidlin-6, Aidlin-7, and Aidlin-9 production wells showed significant decreases in NCG. A trend of decreasing NCG concentration indicates that an increasing fraction of injection derived steam (IDS) is being produced over time. Both the lowering of NCG and increased production of IDS are more apparent by comparing NCG contour maps before (2003, Figure 2) and after (2009, Figure 3) the startup of injection into Aidlin-11. Figure 2 is a contour map of the NCG concentrations of well steam in parts per million by weight (ppmw) prior to the startup of Aidlin11 injection. Data are plotted at the midpoint of the production zone, not the wellhead, since all the wells are directionally drilled. In 2003 the highest NCG well, Aidlin-9, in the field was over 55,000 ppmw, and the NCG low was centered in the western portion of the wellfield. NCG 

located in the northwest portion of the field. Figure 3 shows the NCG concentrations in 2009, after five years of Aidlin-11 injection service. As shown in Figure 3, the highest NCG dropped to just over 35,000 ppmw, and the NCG low shifted to the eastern portion of the wellfield. Moreover, Aidlin-9 NCG concentration has dropped to just under 15,000 ppmw. Clearly Aidlin11 has had a major affect on the NCG concentrations of Aidlin production wells.

\section{Aidlin-11 Tritium Tracer Test Results}

On 5/5/2008, 300 curies of tritium tracer were injected into the reservoir via the SRGRP pipeline. The tracer was distributed to all injection wells receiving SRGRP water, including Aidlin-11. Steam condensate samples have been periodically collected from all production wells in the Aidlin field and analyzed for tritium activity. The tracer activity curves for each Aidlin production well is shown in Figure 4. Tracer recovery at Aidlin is generally low and slow as shown in past tests as well as this one. Two wells, Aidlin-4 and Aidlin-6, showed an early (day 14 of the test) return of tracer. This indicates that there is a somewhat direct reservoir path from the boiling front of Aidlin-11 injectate to Aidlin-4 and Aidlin-6 fractures producing IDS. The remaining wells beginning with Aidlin 9 on Day 71, experienced tritium breakthrough much later, indicating a much longer residence time of the injected fluid in the reservoir before injection derived steam is produced from the well. This is an indication of low reservoir permeability in the Aidlin area. Figure 4 shows that the peak tritium activity appears to have passed at about day 280 . Note that tritium has not been detected in Aidlin-10. This well has had high NCG concentrations in recent years and the tritium test confirms that it is in poor communication with the other Aidlin wells. Figure 5 is a contour map of the maximum tritium detected with interpretative arrows showing the path of produced IDS. These directions are compatible with the contours of low NCG in Figure 3. 
DE-FC07-02ID14405; Amendment No. M006

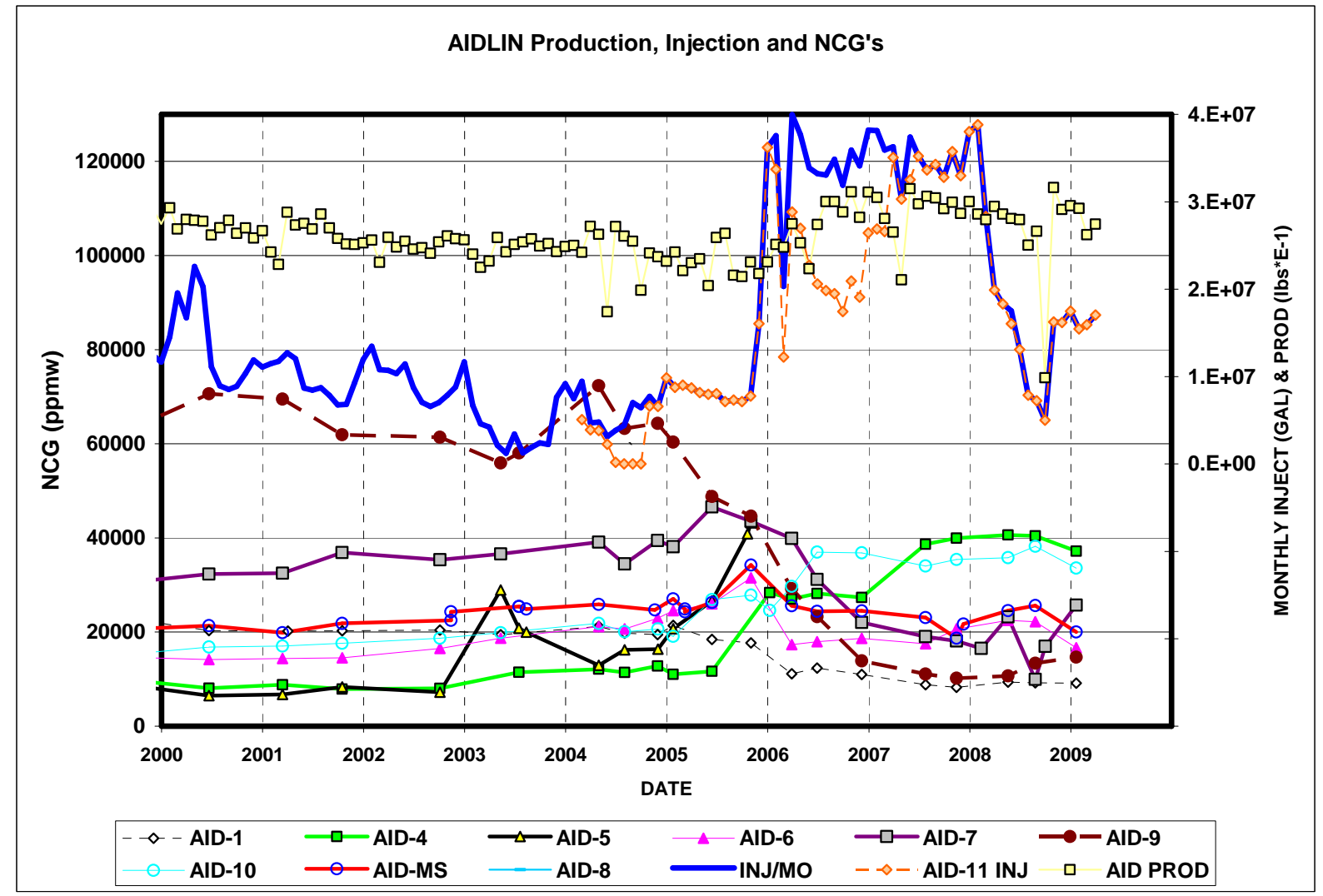

Figure 2 


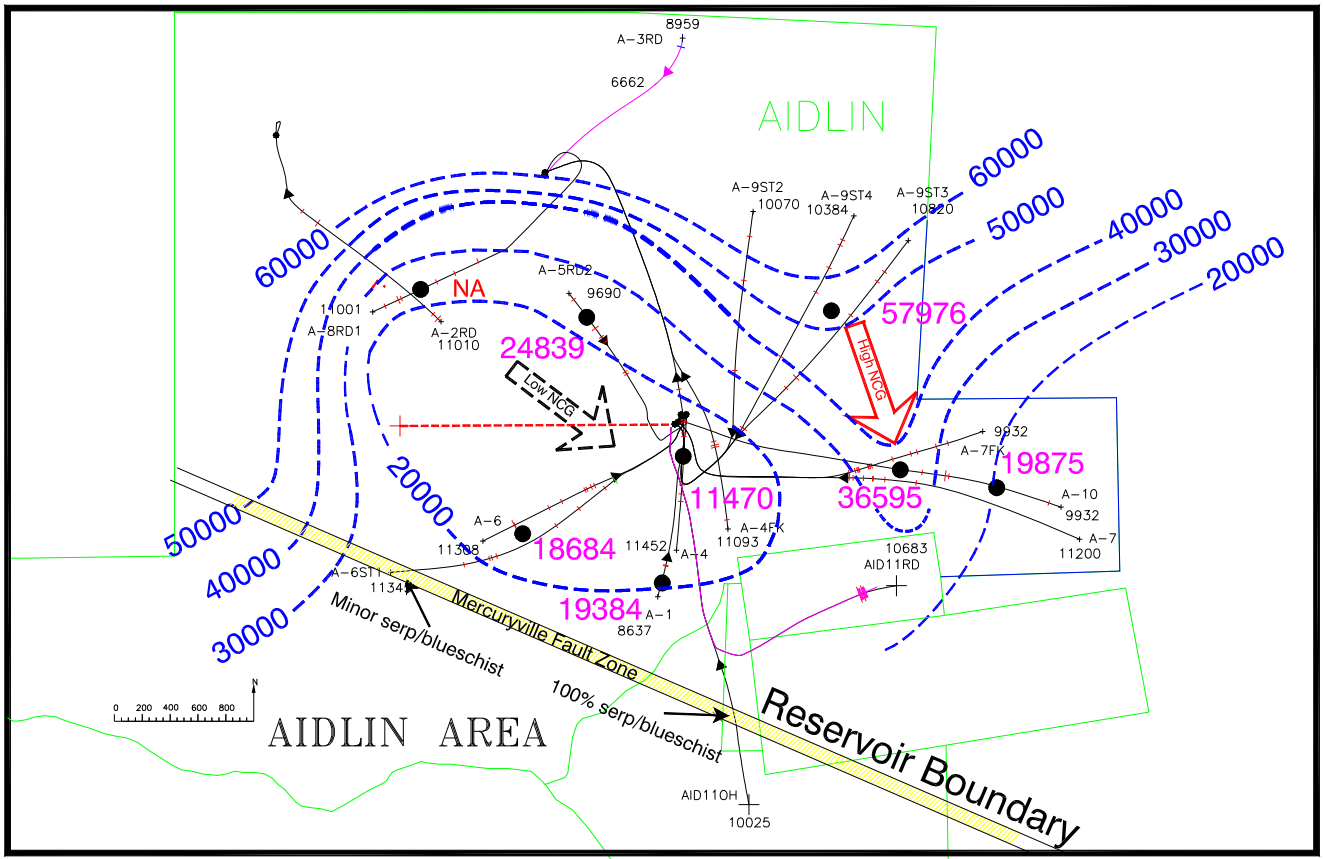

2003 NCG concentrations in Aidlin steam.

Figure 3

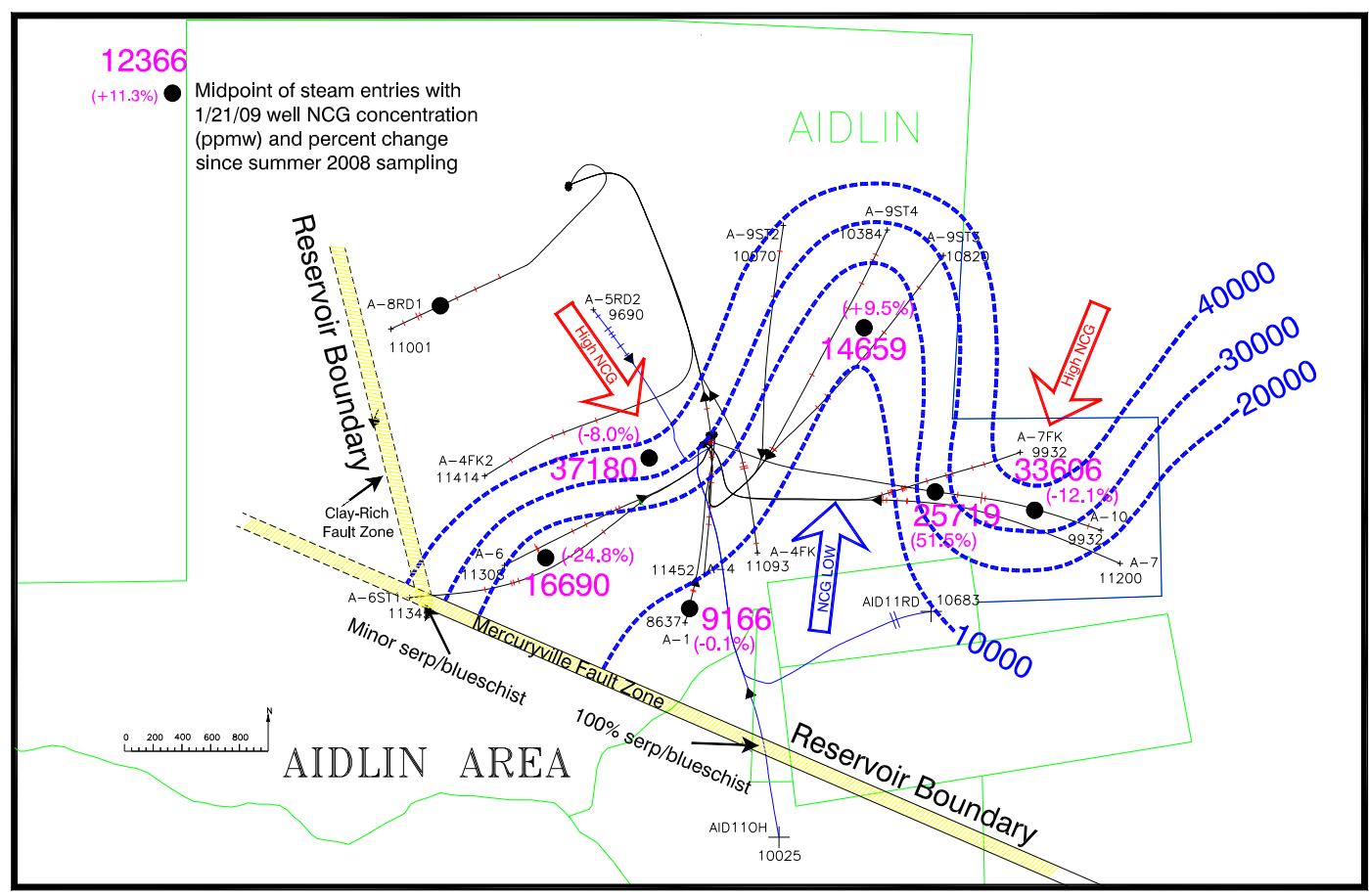

Winter 2009 NCG concentrations (ppmw) in Aidlin steam

Figure 4 
DE-FC07-02ID14405; Amendment No. M006

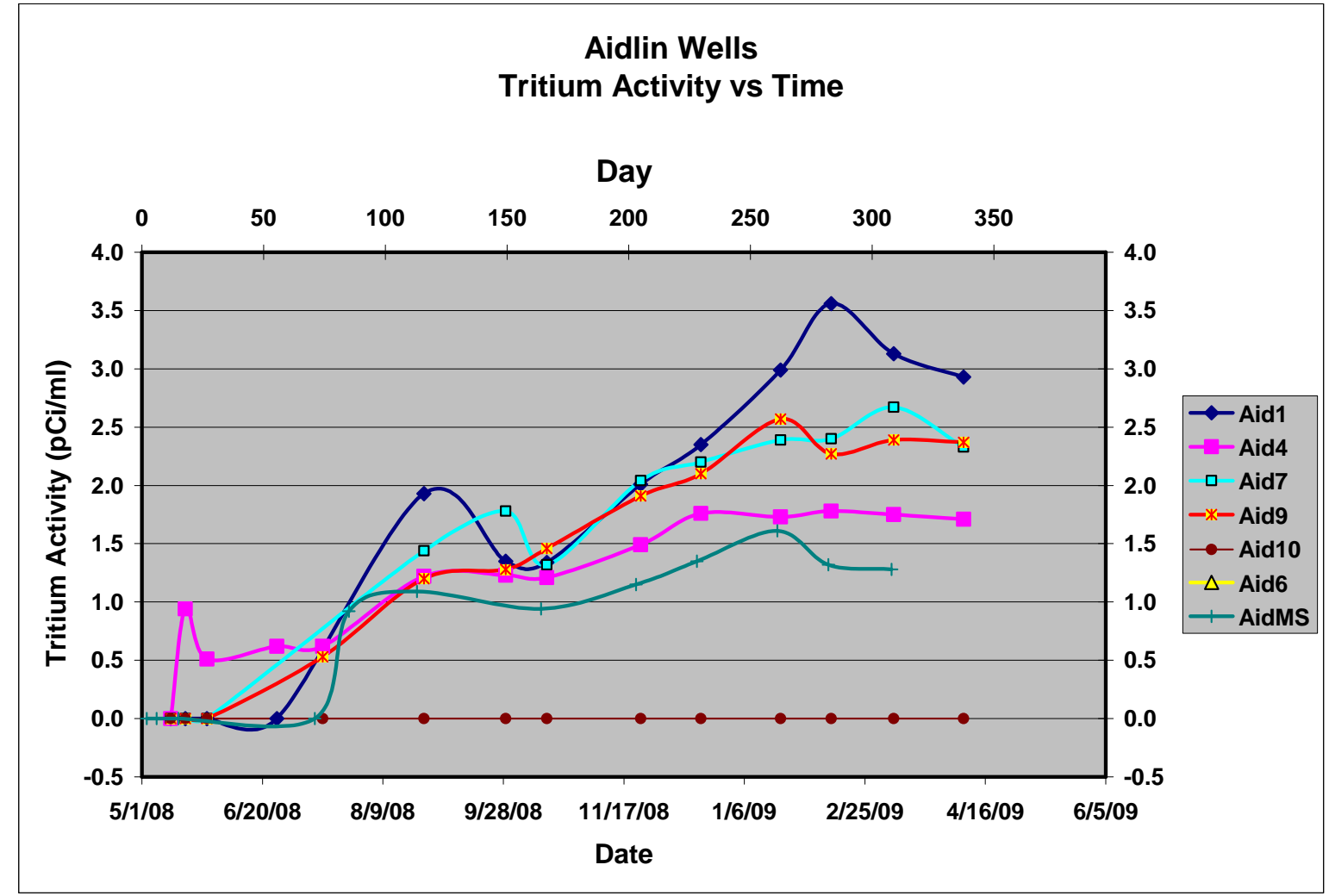

Figure 5

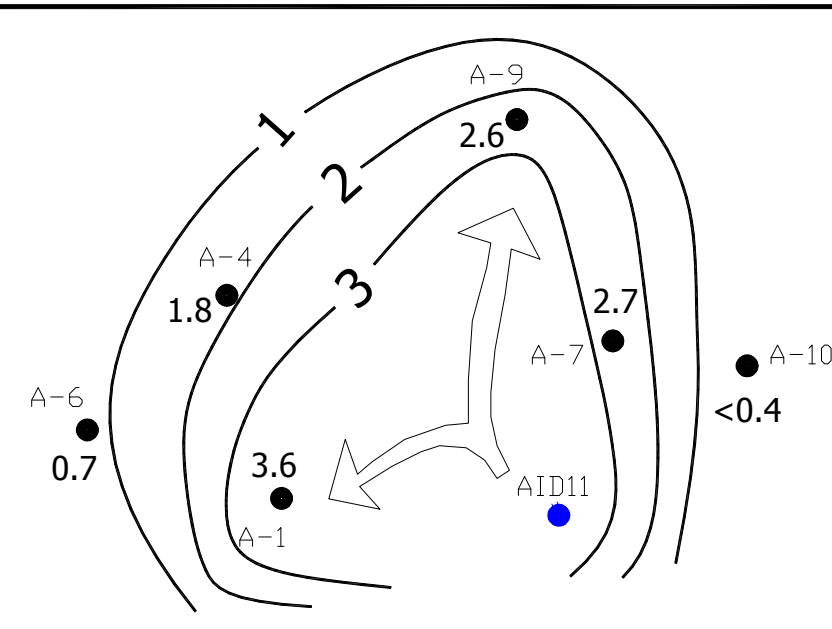

Maximum Tritium to date in Aidlin Steam. $(\mathrm{pCi} / \mathrm{ml})$. 


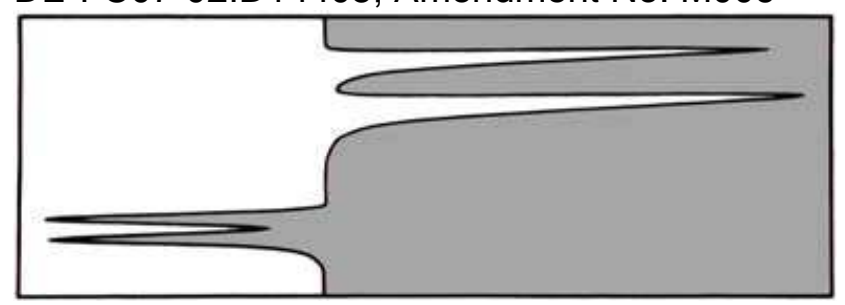

June 24, 2009

\section{Appendix 2}

Final Report

Full-Scale Dry Steam Scrubbing Test

Abril-2

\section{Background}

The Dry Steam Scrubbing (DSS) process for $\mathrm{HCl}$ removal from geothermal steam has been under development for almost 10 years, beginning with laboratory bench testing, progressing through side-stream field pilot testing, and finally resulting in a full-scale demonstration test conducted at The Geysers well Abril 2, owned and operated by Calpine. The DSS process was intended to help improve the efficiency of geothermal power projects, which are an important source of baseload renewable energy. The process was originally developed by ThermoChem, Inc. to remove corrosive hydrogen chloride $(\mathrm{HCl})$ from geothermal steam without superheat quenching or steam condensation so that the maximum amount of energy can be retained for power generation with a minimal corrosion damage to steam piping and turbines. The DSS process is competitive with the current technology in operating and capital costs, and has the advantage of retaining steam superheat, minimizing corrosion throughout the steam gathering pipelines, and allowing for increases in steam utilization efficiencies.

The corrosion process caused by $\mathrm{HCl}$ in geothermal steam is a dew-point corrosion phenomenon- The $\mathrm{HCl}$ must condense into a liquid phase before corrosion can occur. However, it is possible for the initial formation of moisture, or the dew-point, to occur at temperatures above the steam saturation temperature (Hirtz, 1991). This effect is due to boiling-point elevation caused by high concentrations of dissolved species, typically $\mathrm{NH} 4 \mathrm{Cl}$, in the initial liquid film or droplet. Local heat sinks in the pipeline, such as valves and pipe support brackets, can also result in dewpoint conditions from an otherwise superheated steam flow.

The compilation of chloride data and superheat values at The Geysers over many years by ThermoChem and Calpine shows that several ppm $\mathrm{HCl}$ does not cause corrosion damage provided that the steam superheat is maintained at $40{ }^{\circ} \mathrm{F}$ or more (Beall, 2005). The typical well at The Geysers requiring treatment for $\mathrm{HCl}$ produces steam with superheat above $40 \mathrm{~F}$, and the full-scale DSS process with adequate insulation of the vessel and piping is expected to retain the superheat within 1 or 2 F.

Steam washing with dilute $\mathrm{NaOH}$ has been utilized successfully for many years at The Geysers, California, and Larderello, Italy, to protect steam gathering and power generation equipment (Hirtz, 1990) from corrosion damage. The steam washing equipment, or Corrosion Mitigation 
DE-FC07-02ID14405; Amendment No. M006

Facility (CMF), is installed at the wellhead of high- $\mathrm{HCl}$ wells at The Geysers (10 to $160 \mathrm{ppm} \mathrm{HCl}$ ). There is usually not enough superheat in the steam to allow these wells to produce through the gathering system before mitigation, so chloride must be scrubbed at the wellhead. Additional steam washing (without caustic) is performed at the power plants to remove chloride from other low- $\mathrm{HCl}$ wells $(0.05-5 \mathrm{ppm})$, and residual $\mathrm{HCl}$ from the $\mathrm{CMF}$ wells $(1-5 \mathrm{ppm} \mathrm{HCl})$. In Larderello, most wells have high superheat (100 $\mathrm{\circ})$, so $\mathrm{HCl}$ is allowed to pass through the gathering system and then removed at the power plant. This arrangement is much simpler and more efficient, but not possible at The Geysers due to the generally lower superheat.

The wash water quenches steam superheat and condenses steam, reducing the total enthalpy and mass flow rate. By producing saturated, wet steam from each CMF, the superheat in the entire gathering system is reduced. Severe corrosion can occur when the steam from relatively low-HCl wells, which previously did not require scrubbing, mixes with the wet CMF steam. This creates a vicious cycle where more wells require steam scrubbing to prevent gathering system corrosion. Calpine has suffered from this problem for years, and at one time had weekly corrosion failures occurring in some large steam pipelines. The DSS process uses dry calcium carbonate (calcite) pellets as the absorbing media for $\mathrm{HCl}$. By removing $\mathrm{HCl}$ through the DSS process, without heat loss, the gathering system corrosion problem will be minimized or eliminated.

The DSS process was initially developed through laboratory bench tests and small-scale field pilot tests under a Department of Energy Geothermal Power Initiative Grant (No. DE-FG0700ID13915, reported July 7, 2001) and a California Energy Commission EISG Grant (No. 52929 / 02-13, reported May 31, 2006). The pilot studies were conducted at the Aidlin project at The Geysers, also operated by Calpine. The test results demonstrated that an amine/oil scrubbing process and a solid calcite absorption process can both mitigate $\mathrm{HCl}$ in superheated steam, but only the calcite process is economically viable on a field-wide basis (Hirtz, 2002). The amine treatment process may be useful for downhole injection where water / caustic scrubbing is not practical. Recently a "proprietary" blend of amine and dilute potassium carbonate solution has been promoted by a commercial water treatment company at The Geysers, but the water-based product defeats the purpose of using an organic amine by at least partially quenching superheat, resulting in a corrosive aqueous phase when underfed relative to the $\mathrm{HCl}$ loading as directed (PowerChem, 2009).

Calcite consumption in the DSS process is according to the reaction between calcite and $\mathrm{HCl}$. This process can occur directly between the superheated gaseous phase containing $\mathrm{HCl}$ and the solid calcite substrate, without the presence of liquid water:

$\mathrm{CaCO} 3(\mathrm{~s})+2 \mathrm{HCl}(\mathrm{g}) \square \square \mathrm{CaCl} 2(\mathrm{~s})+\mathrm{H} 2 \mathrm{O}(\mathrm{g})+\mathrm{CO} 2(\mathrm{~g})$

There are no known competing reactions that could occur from geothermal steam exposed to calcite, unlike caustic. Sodium hydroxide reacts rapidly with $\mathrm{CO} 2$ to form sodium carbonate, but is still effective in neutralizing $\mathrm{HCl}$. Excess caustic without sufficient water can result in sodium borate scaling. Due to the very low solubility of calcite at high temperatures (retrograde solubility), there is virtually no calcite dissolved if the material does become wet during steam field operations or "washing" of the calcite bed to remove reaction products.

Under the previous research studies it was demonstrated that up to $160 \mathrm{ppm} \mathrm{HCl}$ could be effectively treated by the DSS process. Wells producing $50 \mathrm{ppm}$ or more $\mathrm{HCl}$ were conservatively 
DE-FC07-02ID14405; Amendment No. M006

estimated to need a calcite bed depth of 72 inches. The first full-scale DSS vessel was designed to accommodate a bed depth up to 96 inches. Changing the bed depth to optimize chloride removal and to minimize pressure drop is a simple matter of adding or removing calcite pellets, and this optimization procedure was intended to be performed during the full-scale test. The prior work had shown that "Reflux Regeneration" was the most effective means to remove reaction products from the calcite bed and maintain long-term performance. This is accomplished by shutting-in the outlet pipe from the vessel for several hours while leaving the inlet open and the drain valve partially open. Calcite bed regeneration about every 30 days was found to maintain the outlet chloride at a constant level for the conditions tested.

In the early pilot testing, chloride concentrations were reduced down to about $2 \mathrm{ppm}(+/-1 \mathrm{ppm})$, regardless of the inlet chloride over the range of 6 to $160 \mathrm{ppm}$. This is sufficient to prevent corrosion in gathering systems under most circumstances. The steam temperature will increase in sections of the gathering system where DSS replaces the CMF process. The mitigation of general gathering system corrosion by reducing $\mathrm{HCl}$ from high-chloride wells while maintaining superheat is the greatest advantage of the DSS process over the current CMF technology.

Some high-chloride steam wells at the Geysers have become isolated in areas of moderate chloride and reasonably high superheat. The steam from the low to moderate chloride wells can be produced without treatment if the superheat is maintained, but a high-chloride well always requires treatment. The conventional CMF system desuperheats the steam in the process of removing chloride, resulting in wet, low-chloride steam mixed with dry, moderate-chloride steam in the main gathering system. This lowers the overall superheat of the combined steam and causes corrosion damage in the large cross-country steam lines to the power plants. In some cases these wells cannot be produced and become isolated for this reason. This situation varies greatly by region and over time as areas "dry-out' and become more superheated, or with changes in injection water rates and targets, which may reduce both superheat and $\mathrm{HCl}$ levels.

The operating cost of the DSS process, based on chemical usage alone, is less than $30 \%$ the cost of the conventional CMF process. The CMF caustic scrubbing process requires an excess of $\mathrm{NaOH}$ relative to $\mathrm{HCl}$, due to various side reactions including boric acid neutralization and CO2 hydration, which contributes to the higher operating cost (Hirtz, 1991). The capital cost of the DSS process is about the same or less than the CMF process, depending on the number of vessels required. General maintenance and manpower requirements for the DSS system are higher, dependent on regeneration and reloading frequency for the calcite bed, which varies with $\mathrm{HCl}$ concentration and steam flow. One of the goals of the Abril 2 test was to obtain data on maintenance requirements and logistical issues, so we could design a full-scale DSS vessel optimized specifically for this purpose

Given the success of the Calcite DSS process in field pilot testing with $\mathrm{HCl}$ inlet concentrations up to $160 \mathrm{ppm} \mathrm{HCl}$, and the need to safely recover steam from wells that had become isolated in areas where superheat must be maintained, a full scale test was proposed by Calpine and ThermoChem for further evaluation. This full scale test was intended to assist in the final process design for implementation on several wells where the DSS is most needed.

\section{Full Scale Test on Abril-2}


The initial pilot test vessel for side-stream testing had a 12-inch diameter cross section, while a single full-scale vessel for The Geysers needs to be about 48 to 54 inches in diameter. Multiple smaller vessels or 'packed pipes' could also be used. The pilot and full-scale vessels used to date are shown in Figures 1 - 4. In sizing a bed up to full scale conditions, the primary consideration was to ensure an even flow distribution and to prevent channeling through the bed. The full-scale vessel used in this latest study was a modified horizontal steam / liquid separator that had been retired from service. The vessel was reconfigured for vertical installation and had sufficient diameter and depth to function as a packed-bed that could accommodate about $50 \%$ of the flow from the test well, Abril-2 $(40 \mathrm{KPH})$. The balance of the steam flow was treated by the CMF process as usual. While many wells at The Geysers could be treated with one vessel of this size, two vessels in parallel would be required to minimize pressure drop for higher flow rate wells (on the order of $100 \mathrm{KPH}$ ). The critical design parameters of the calcite beds used for initial pilot testing and the scaled-up version for Abril-2 are summarized in Table 1. The most important design parameters are steam flow, chloride concentration, bed diameter, depth, steam velocities and pressure drop. The resulting outlet chloride concentrations, removal efficiencies and superheat are listed as average values for some of the original pilot tests and for the recent testing at Abril-2.

As part of the previous work, full-scale DSS vessels and calcite beds had been designed for several candidate wells at The Geysers. The physical configuration and projected operating parameters are also given in Table 1. These vessels are comparable in size to those used for conventional water wash and caustic scrubbing, but could be substantially modified from the Abril 2 vessel since they would not have to be based on an existing vessel and could be optimized for performance and lower maintenance.

The Abril-2 DSS was brought on-line on July 14, 2008. The initial flow rate through the DSS vessel was about $40 \mathrm{KPH}$, with $30 \mathrm{KPH}$ flowing through the CMF, and both and recombining before the main steam pipeline. Five sets of steam condensate samples for chloride analysis were collected upstream and downstream of the DSS by ThermoChem over the course of the 22 day test, through August 4th, 2008. Pressure, temperature, pressure drop, and superheat were also determined. The pressure drop remained at about 2 psig during the course of the test, reaching a maximum of 2.9 psig before the well was shut-in. An average of about 4 F superheat was lost through the vessel, due to inadequate insulation. The superheat loss was higher at lower steam flow rates near the end of the test when the well was experiencing problems unrelated to the DSS. The DSS was shut-in August 6th, 2008, and not returned to service due to mechanical CMF separator problems. All of the test data is summarized in Table 2.

The average chloride removal efficiency was $92 \%$, and no decline in efficiency was measured for the duration of the test, as shown in Figure 5. Although the efficiency was high, the residual chloride in the outlet steam was higher than in previous pilot tests where the inlet chloride was also high (Aidlin 9). Previous work had demonstrated that outlet chloride would level-off at 2 to 3 ppm regardless of inlet concentration, up to at least $160 \mathrm{ppm}$. The Abril-2 outlet chloride averaged about $7.5 \mathrm{ppm}$. This may have been the result of flow channeling through the bed, where a narrow steam pathway exists with less contact between steam and calcite than in the bulk bed matrix. There is some evidence of this in the pressure drop, which was lower than expected. The measured pressure drop was about 1 psid lower than calculated. In previous tests the measured value agreed well with the calculated, or was slightly higher. 
Final Report

June 29, 2009

DE-FC07-02ID14405; Amendment No. M006

The Ergun function (Ergun, 1952) was used to predict the pressure drop as a function of steam flow, pressure, temperature, bed pellet size, depth and diameter through the packed beds:

$$
\frac{\Delta P}{L}=150 \frac{\mu G}{k g \rho D^{2}} \frac{(1-\varepsilon)^{2}}{\varepsilon^{3}}+1.75 \frac{G^{2}}{\kappa g \rho D} \frac{(1-\varepsilon)}{\varepsilon^{3}}
$$

where the variables represent the following parameters:

$\Delta P=$ pressure drop, lb./in.2

$L=$ depth of the packed bed, $\mathrm{ft}$.

$G=\rho V=$ mass velocity, lb./hr.-ft.2

$\mathrm{V}=$ superficial linear velocity, $\mathrm{ft} . / \mathrm{hr}$.

$\rho=$ fluid density, lb/ft.3

$\mu=$ fluid viscosity, lb./hr.-ft.

$D=$ effective particle diameter, $\mathrm{ft}$.

$\varepsilon=$ inter-particle void fraction, dimensionless

$g=$ gravitational constant, $4.17 \times 108 \mathrm{lb} . \mathrm{ft} . / \mathrm{lb} .-\mathrm{hr} .2$

$k=$ conversion factor, 144 in. 2 /ft.2

Although a low pressure drop is desirable, it must not be the result of flow channeling and poor contact. A practical upper limit of approximately 5 psid is considered ideal for Geysers wells based on well output modeling performed by Calpine's reservoir engineers at The Geysers (Conant, 2004). These criteria constrained the initial design of the full-scale test beds for the DSS process, as bed design must balance $\mathrm{HCl}$ removal efficiency versus pressure drop.

Since the Abril 2 test only ran 3 weeks, and there was no decline in efficiency during that period that triggered the need for a regeneration of the bed to remove reaction products, regeneration was not performed earlier. It is likely that the system could have run for 30 days or more between washes, but we were unable to make any determination of the regeneration frequency needed. Abril-2 represents the extreme upper end for corrosive steam to be treated by this process, as it is one of the highest $\mathrm{HCl}$-producing wells in The Geysers. Thus a regeneration interval of 30 days would be considered very good. A DSS system on a typical Geysers well producing 10 to $30 \mathrm{ppm}$ $\mathrm{HCl}$ could likely be in service for 3 to 6 months without any maintenance.

A pilot test wash down procedure was developed for Abril-2, based on earlier testing, to regenerate the calcite within the DSS by washing away accumulated reaction products $(\mathrm{CaCl} 2)$ on the surface of the calcite pellets. The calcium chloride byproduct is highly soluble in water and readily rinsed-off. Solids found at the bottom of the DSS vessel following the pilot testing vessel were primarily corrosion products from the well (iron), mixed with some reaction products. The calcite is consumed in the process and eventually the bed has to be replenished with fresh calcite, but it does not have to be re-filled after every wash. Table 1 lists the consumption rate (loss rate in lbs./month) expected for calcite in each bed design, which is a function of $\mathrm{HCl}$ concentration and steam flow.

Each DSS bed begins with a large excess of calcite. The Abril-2 DSS was started-up with an 83 inch bed depth- $8,400 \mathrm{lbs}$. of calcite. This was a conservative starting point since the well is very high in $\mathrm{HCl}$. It was planned to run tests at shallower bed depths to determine the sensitivity of efficiency to depth and optimize future designs in order to lower capital and maintenance costs. 
Final Report

June 29, 2009

DE-FC07-02ID14405; Amendment No. M006

Shallower bed depth means smaller vessels, less material handling at each fill, etc. Unfortunately the testing was cut short and these goals could not be achieved.

Operation of the Abril-2 well was completely suspended on September 4, 2008 for reasons that included repair of the wellhead separator, and remains suspended due to the high concentration of NCG which compromised the operation of the Geysers Unit 11 power plant. At this time, Abril-2 will not be returned to service until the non-condensable gas concentrations can be lowered through the injection of water into OF27A-2. The conversion of OF27A-2 to an injection well is presently anticipated in early 2010.

\section{Further Work}

The DSS process is nearly commercial for The Geysers and only requires some longer-term testing to optimize the process design and minimize operation and maintenance costs, which are primarily manpower to load, clean and re-fill the vessels. Some options for more efficient operations would be horizontal, shallower-bed vessels which would be closer to the ground and easier to service, multiple horizontal "packed pipes" (18 - 24 inch diameter) with basket-loaded beds that could be easily slipped in and our for washing and refill, and fluidized bed designs that would be continuous duty. The fluidized bed concept uses smaller diameter calcite pellets that become suspended in the upward steam flow. Spent material would be separated by a conventional cyclone integral to the vessel, and the calcite would be replenished using a slurry pump and an aqueous calcite suspension for the feedstock. Fluidized beds can be highly efficient due to good gas / solid contact.

Previous analyses by Calpine indicated that the installation of a DSS system on a single well in the Unit 7 Ridgeline area of The Geysers is expected to eliminate 4 outages per year, totaling 12 hrs each, due to corrosion failures caused by CMF steam mixing with superheated steam from other wells feeding the same pipeline. The intermittent shutdown of the 5 wells feeding this pipeline results in the loss of $576,000 \mathrm{kWh}$ of power per year, or $\$ 37,000$ in electric sales. The corrosion damage repair cost is $\$ 15,000$ per year. The payback for installation of the DSS system is 3 years, with an accumulative pre-tax cash flow of $\$ 407,500$ after 10 years (Conant, 2005).

Similar savings were expected in other areas of The Geysers where CMF steam mixes with superheated steam in the gathering system pipelines. The economics and technical needs may now be different, so Calpine will have to determine if there is sufficient incentive to continue the development of this technology for The Geysers.

ThermoChem has an exclusive license to the general technology as covered under a patent by Unocal (US Patent No. 5,879,433). Through the sale of The Geysers assets from Unocal to Calpine in 1999, the right to use this technology royalty-free was passed onto Calpine.

ThermoChem is currently working on the design of a fluidized DSS bed for the Icelandic Deep Drilling Project (IDDP), where supercritical fluids with very high $\mathrm{HCl}$ content are expected to be produced. Under a proposal to DOE in response to FOA DE-PS36-09GO99019, ThermoChem would design a DSS system to treat steam produced from an EGS demonstration project in Hawaii where very high levels of $\mathrm{HCl}$ are also expected as the result of contacting water with rock at extreme temperatures (magma exploitation project).

\section{Figure 1 Aidlin-4 and 9 Pilot-Test DSS Vessel}


Final Report

June 29, 2009

DE-FC07-02ID14405; Amendment No. M006

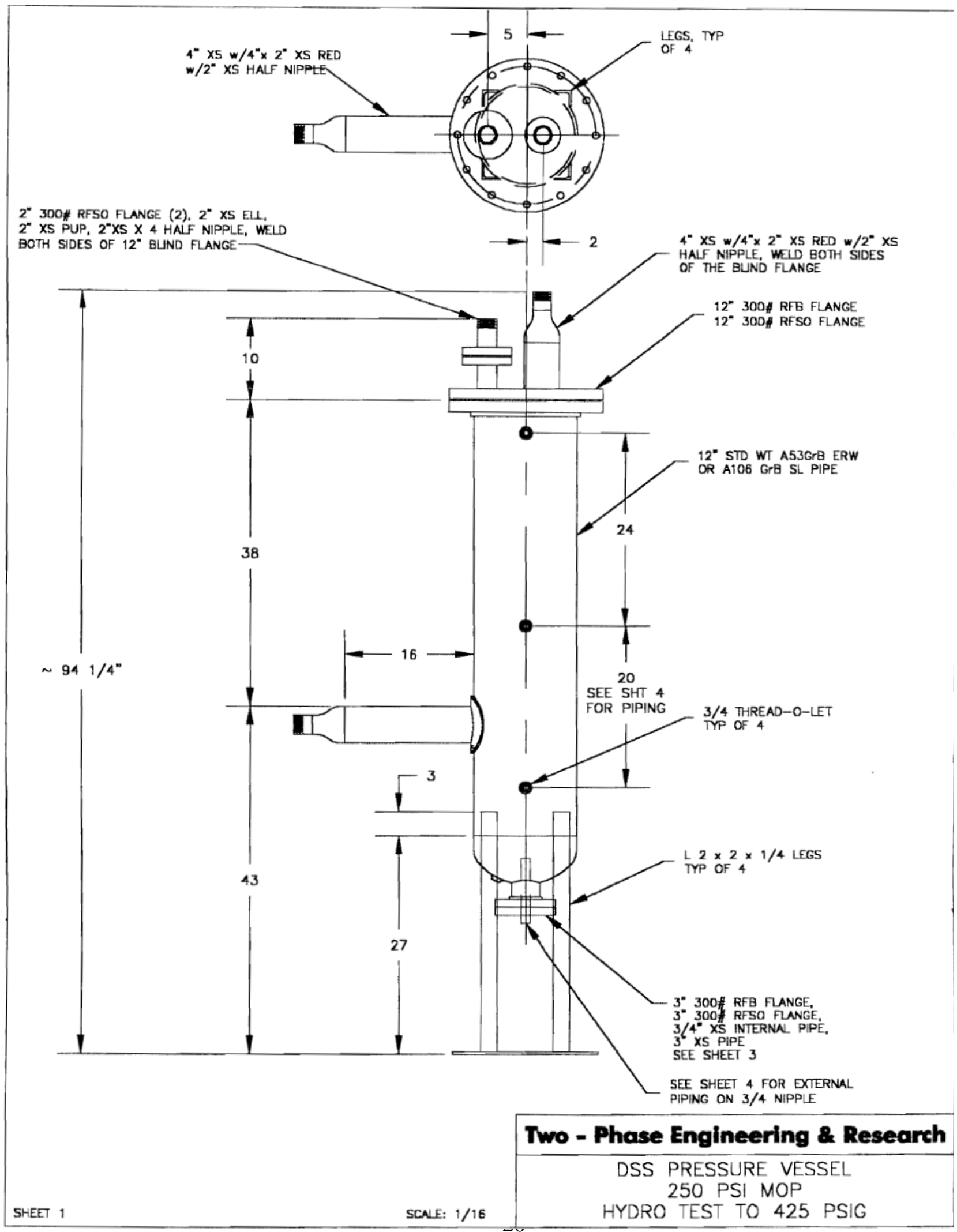


Final Report

June 29, 2009

DE-FC07-02ID14405; Amendment No. M006

Figure 2 Pilot-Test DSS Vessel at Aidlin-4

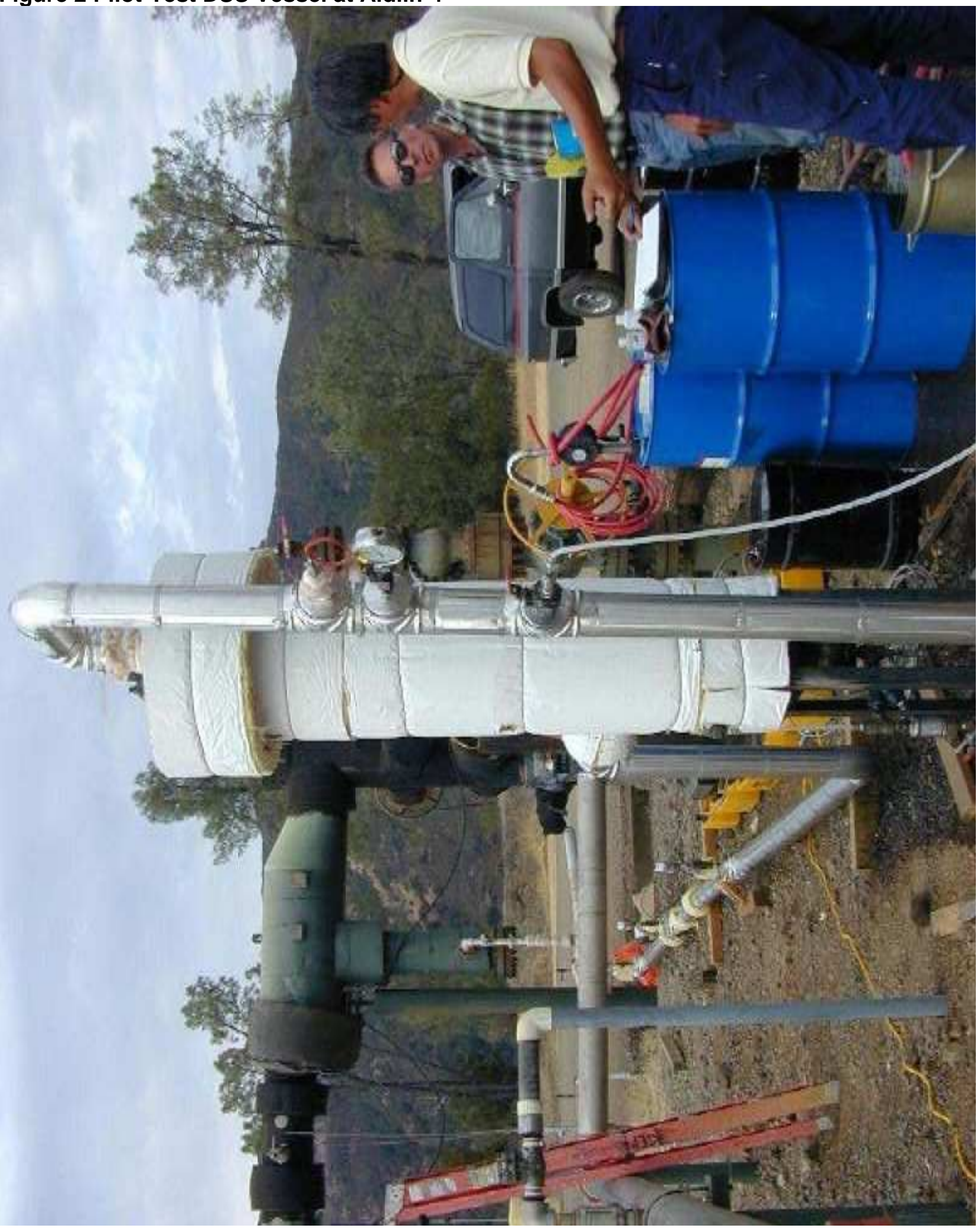


DE-FC07-02ID14405; Amendment No. M006

Figure 3 Full-scale DSS Vessel

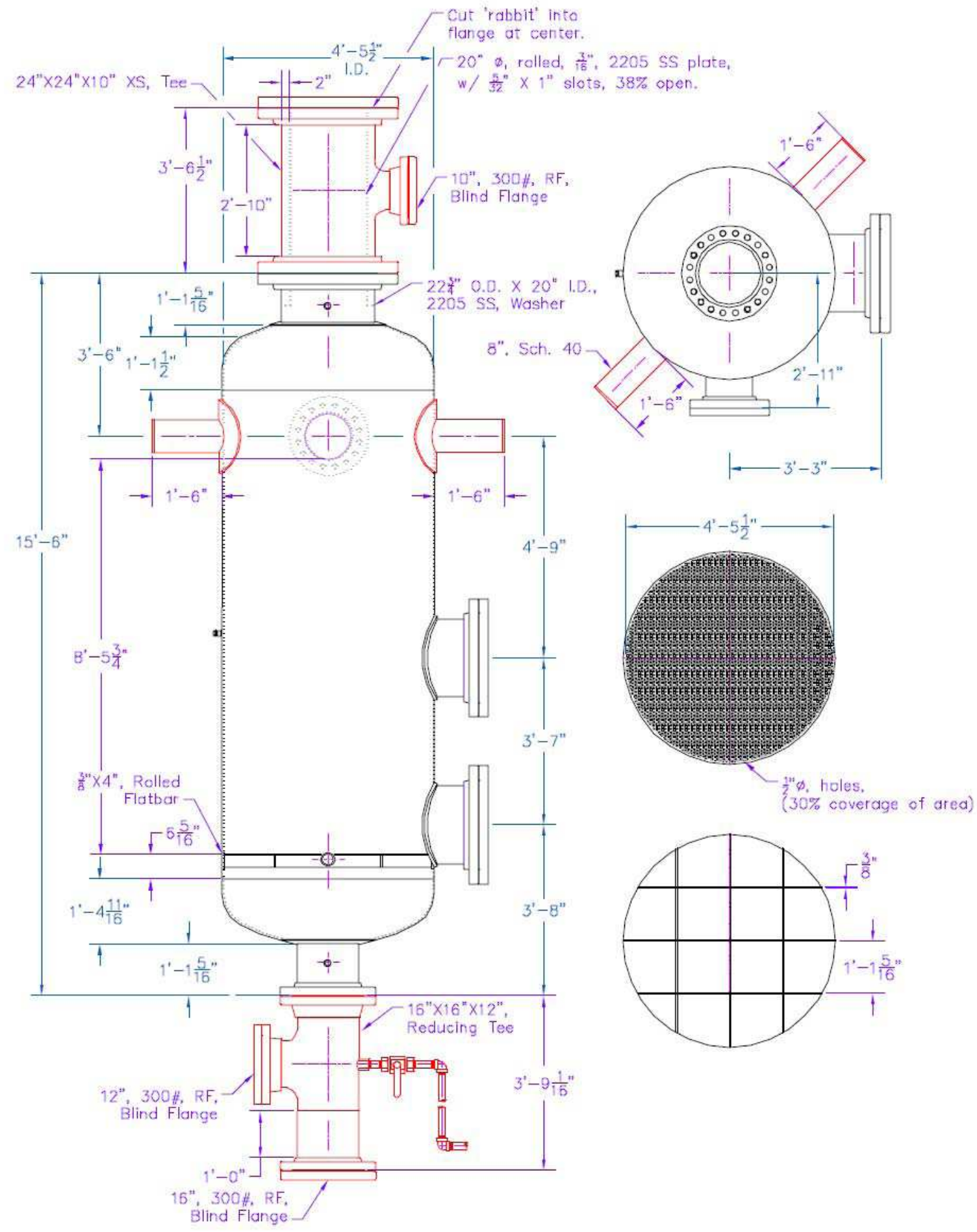




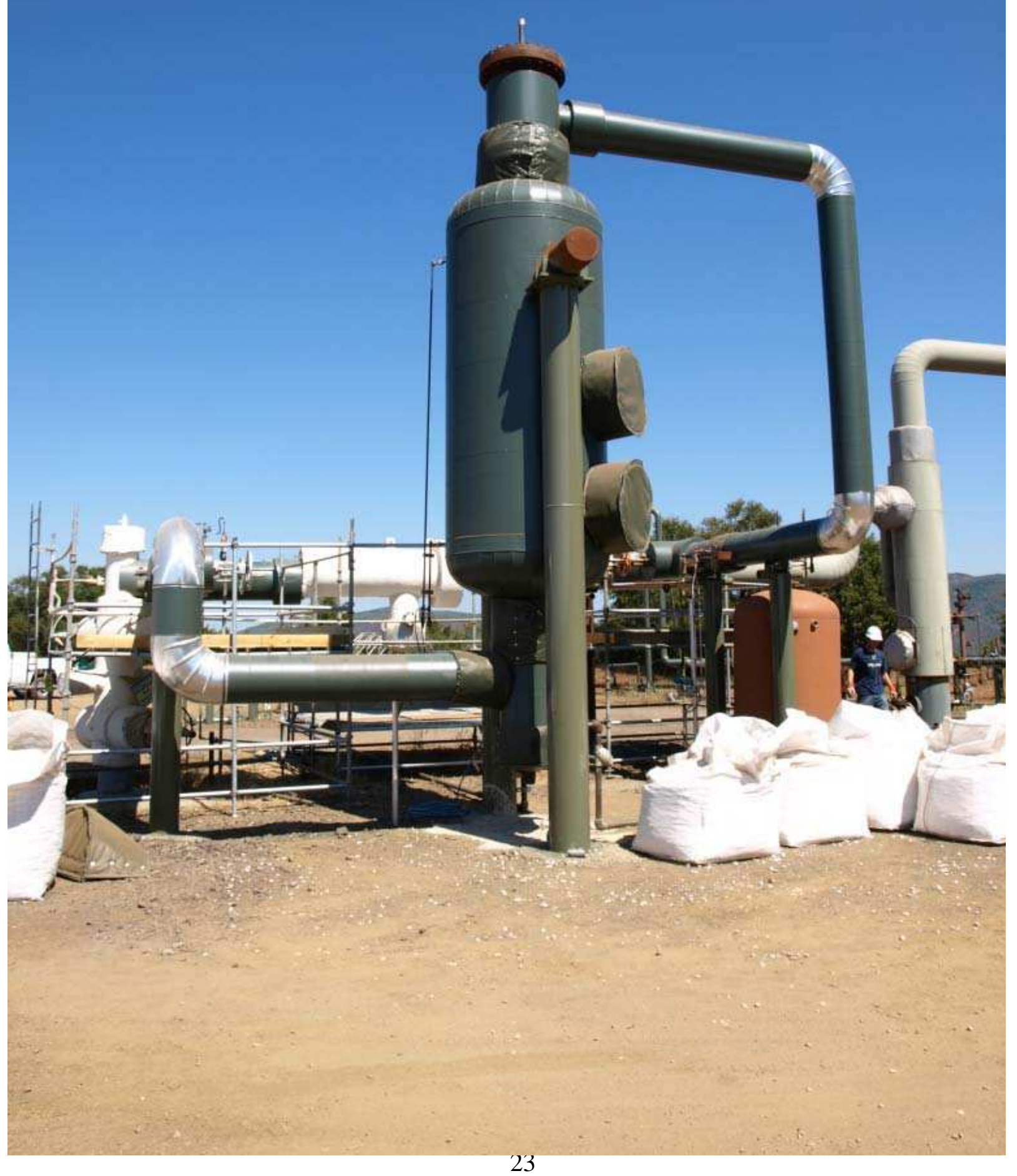




\begin{tabular}{|c|c|c|c|c|c|c|c|c|c|c|c|c|c|}
\hline Date & Day & $\underline{\text { Inlet CI }}$ & $\underline{\text { Outlet } \mathrm{Cl}}$ & $\%$ removed & $\underline{\text { Steam Flow }}$ & Inlet $P$ & $\underline{\text { Outlet P }}$ & $\underline{\mathrm{DP}}$ & Inlet Temp & $\underline{\text { Inlet SH }}$ & $\underline{\text { Outlet Temp }}$ & $\underline{\text { Outlet SH }}$ & $\Delta \mathrm{SH}$ \\
\hline 7/14/08 & 0 & $91.5 \mathrm{ppm}$ & $6.51 \mathrm{ppm}$ & $92.9 \%$ & $42000 \mathrm{lbhr}$ & $115.7 \mathrm{psig}$ & $112.7 \mathrm{psig}$ & $3.0 \mathrm{psi}$ & $407.5 \mathrm{~F}$ & $60.6 \mathrm{~F}$ & $403.5 \mathrm{~F}$ & $58.4 \mathrm{~F}$ & $2.2 \mathrm{~F}$ \\
\hline 7/118/08 & 4 & $91.2 \mathrm{ppm}$ & $7.29 \mathrm{ppm}$ & $92.0 \%$ & $37500 \mathrm{lb} / \mathrm{hr}$ & $119.7 \mathrm{psig}$ & $117.6 \mathrm{psig}$ & $2.1 \mathrm{psi}$ & $407.0 \mathrm{~F}$ & $57.7 \mathrm{~F}$ & $403.2 \mathrm{~F}$ & $55.1 \mathrm{~F}$ & $2.6 \mathrm{~F}$ \\
\hline $24 / 08$ & 10 & $115.0 \mathrm{ppm}$ & $9.19 \mathrm{ppm}$ & $92.0 \%$ & $36000 \mathrm{lb} / \mathrm{hr}$ & $120.0 \mathrm{psig}$ & $118.0 \mathrm{psig}$ & $2.0 \mathrm{psi}$ & $409.1 \mathrm{~F}$ & $59.6 \mathrm{~F}$ & $405.0 \mathrm{~F}$ & $56.7 \mathrm{~F}$ & $2.9 \mathrm{~F}$ \\
\hline 8/11/08 & 18 & $91.3 \mathrm{ppm}$ & $7.80 \mathrm{ppm}$ & $91.5 \%$ & $37500 \mathrm{lb} / \mathrm{hr}$ & 117.9 psig & 114.2 psig & $3.7 \mathrm{psi}$ & $410.3 \mathrm{~F}$ & $62.1 \mathrm{~F}$ & $404.1 \mathrm{~F}$ & $58.1 \mathrm{~F}$ & $4.0 \mathrm{~F}$ \\
\hline 8/4/08 & 21 & $78.0 \mathrm{ppm}$ & $6.62 \mathrm{ppm}$ & $91.5 \%$ & $25000 \mathrm{lb} / \mathrm{hr}$ & 112.3 psig & 109.0 psig & $3.3 \mathrm{psi}$ & $411.9 \mathrm{~F}$ & $67.1 \mathrm{~F}$ & $400.6 \mathrm{~F}$ & $57.8 \mathrm{~F}$ & $9.2 \mathrm{~F}$ \\
\hline & 93.4 ppm & $48 \mathrm{ppm}$ & $2.0 \%$ & $5600 \mathrm{lb} / \mathrm{hr}$ & 117.1 psig & $114.3 \mathrm{psig}$ & $2.8 \mathrm{psi}$ & $409.2 \mathrm{~F}$ & $61.4 \mathrm{~F}$ & $403.3 \mathrm{~F}$ & $57.2 \mathrm{~F}$ & $2 \mathrm{~F}$ \\
\hline
\end{tabular}

Figure 5 Full-scale DSS Process Results for Abril 2

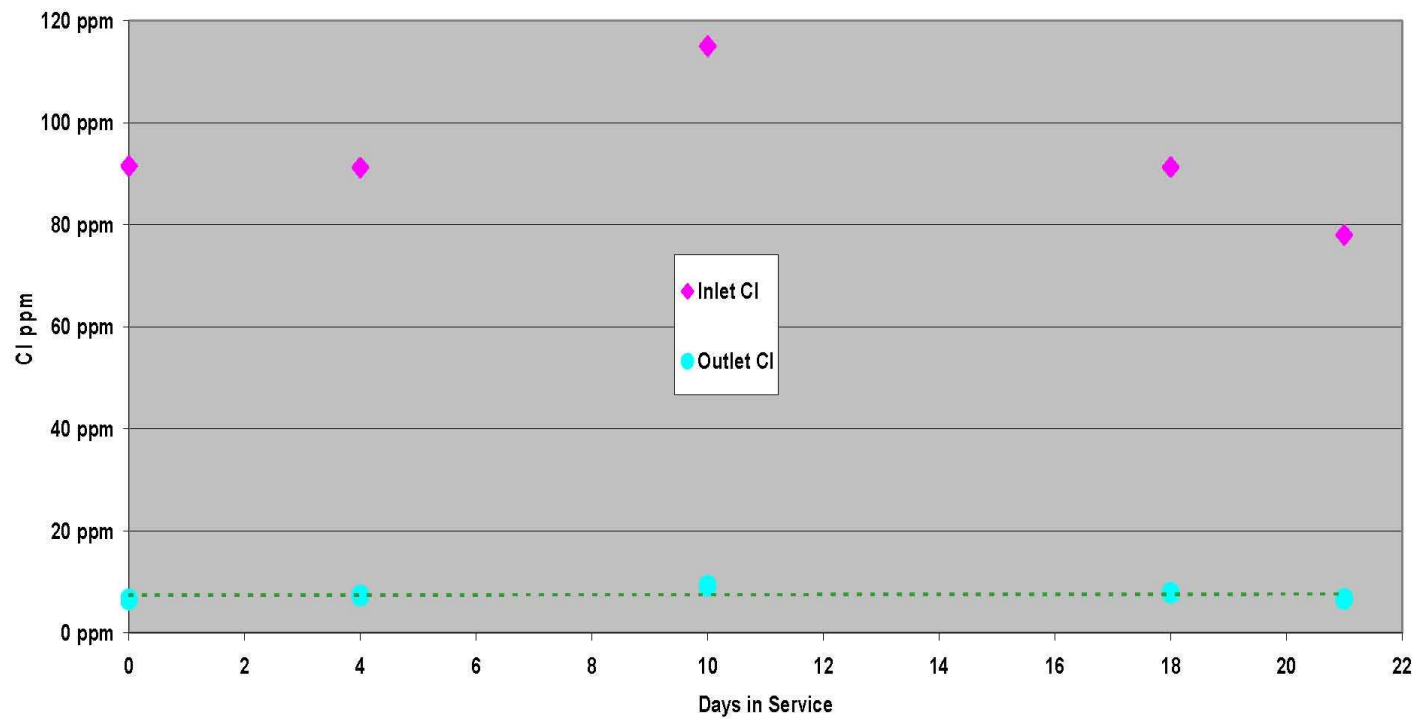

\section{References}

Beall, J., Calpine Internal Report, 2005

Conant, T., Calpine, personal communication, 2004

Conant, T., Calpine Internal Report, 2005

Jung, D., Two-Phase Engineering, personal communication, 2006 
Final Report

June 29, 2009

DE-FC07-02ID14405; Amendment No. M006

Ergun, S., Fluid Flow through Packed Columns, Chemical Engineering Progress, 48, No. 2, 89, 1952.

Hirtz, P., Miller, J., and Prabhu, E., "Operational Results of a Dry-Steam Resource Chloride Corrosion Mitigation System"; Geothermal Resource Council Annual Meeting, Transactions, 1990.

Hirtz, P., Buck, C, and Kunzman, R., "Current Techniques in Acid-Chloride Corrosion Contro and Monitoring at The Geysers"; Proceedings, Sixteenth Workshop on Geothermal Reservoir Engineering, Stanford Geothermal Program, Stanford University, pp. 83-95, 1991.

Hirtz P. N., Broaddus M. L., Gallup D. L., "Dry Steam Scrubbing for Impurity Removal from Superheated Geothermal Steam"; Geothermal Resource Council Annual Meeting, Transactions, 2002.

Stapleton, M., PowerChem memorandum to Bottle Rock Power, "Comparison of GeoGuard 8872 vs. caustic for control of steam line corrosion at Bottle Rock", April 22, 2009

\section{Glossary}

CMF - Corrosion Mitigation Facility, term used at The Geysers to refer to the current water/caustic scrubbing process for $\mathrm{HCl}$ removal from steam

DSS- Dry Steam Scrubbing, the subject of the research in this report, a chemical process to remove $\mathrm{HCl}$ from steam without using liquid water which reduces the steam temperature and overall heat content.

KPH- kilo-pounds per hour (1 KPH = $1000 \mathrm{lbs} . / \mathrm{hr})$

$\mathbf{N a O H}$ - Sodium Hydroxide, used in the CMF process (also known as caustic or caustic soda).

$\mathbf{H C l}$ - Hydrogen chloride (gas) or hydrochloric acid (when dissolved in water).

Superheat - The quantity of heat present in steam, expressed in degrees of temperature above the saturation temperature (condition where steam exists in equilibrium with liquid water). Superheated steam is always dry (contains no liquid water), while saturated steam may be dry or present with liquid water.

Interstitial Velocity- The average velocity of a fluid as it passes through a porous media.

Superficial Velocity- The theoretical velocity of a fluid as it passes through a conduit containing another media or phase, assuming that the media or other phase is not present (flow assumed through entire cross-sectional area of conduit). 


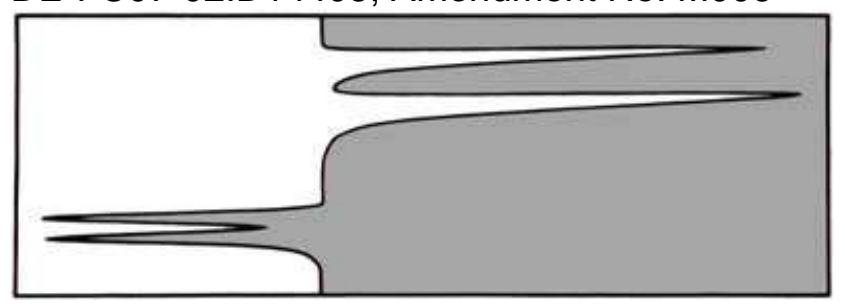

\section{Appendix 3 \\ Final Report \\ High-Temperature/ Two-Phase Sampling Tool ThermoChem DHS}

\section{DHS Tool Background}

ThermoChem, Inc. and Sandia National laboratory collaborated in the development of a downhole sampling tool (DHS) to collect fluid samples from geothermal steam wells during the during the period of 1996 to 1999. Previous samplers based on flow-through or evacuated sample chamber designs were not suitable for two-phase or dry steam wellbore conditions. These devices collect a fixed volume sample of steam under pressure, which results in only a few grams of steam condensate and a very small quantity of non-condensable gas after cooling at the surface. The ThermoChem / Sandia design utilized a eutectic material, with a high heat of fusion, surrounding the sample chamber in order to cool and condense the steam as the eutectic melted and absorbed the heat. This allowed collection of $100 \mathrm{~g}$ of condensate, plus non-condensable gas under pressure.

ThermoChem later developed a two-phase version of the DHS by designing a eutectic pre-cooler before the sample chamber that provided a greater heat capacity and larger sample volume. The pre-cooler and sample chamber incorporated thermistors for precise temperature measurement and calculation of the total heat content of the sample. This made it possible to estimate the total enthalpy of the collected sample, and reconstruction to wellbore conditions for samples collected under two-phase (brine and steam) flowing conditions. This version of the tool was successfully deployed several times in The Philippines during 2004 and early 2005 under two-phase wellbore conditions.

In order to better accommodate the capture and analysis of corrosive gases in geothermal steam as found at The Geysers ( $\mathrm{H} 2 \mathrm{~S}, \mathrm{HCl}$ ), trace metals and low-pH fluids, a new tool was designed with a titanium flow path, cooler and sample chamber. A longer heat shield was designed to house the new, larger components. More robust solenoid valves were designed and benchtested. The sub-assembly was re-designed to allow both external pressure and temperature measurement with sample collection at the same time. A new computer was designed to allow for additional data channels and better resolution for both PT logging capabilities and sample heat content measurement. These upgrades were partially funded by a Department of Energy Grant through Calpine Corporation totaling $\$ 62,000$ in late 2005. The grant money was used to help cover the cost of engineering design, hardware for the titanium eutectic cooler, sample chambers, new heat shield, solenoid valves, instrumentation and part the prototype computer. This work was completed in late 2005, with the exception of the new computer. The upgraded DHS was successfully run in wells at Puna, Hawaii, and Salak, Indonesia during 2007. The new prototype 
Final Report

June 29, 2009

DE-FC07-02ID14405; Amendment No. M006

computer was received in 2008 from Sandia National Labs (privately contracted by

ThermoChem) and tested in early 2009.

\section{Results- The Geysers 2009}

The upgraded DHS tool was deployed at The Geysers during February 2009 in selected wells after the initial dummy-tool and PTS logs were completed. The dummy-tool was used to identify any potential mechanical issues in the wellbores that might prevent running to the target depth and/or risk safe retrieval of the PTS and DHS tools.

This final report includes the results of sampling two steam wells at The Geysers, at depths ranging from 4000 to 6000 feet, demonstrating vertical geochemical profiles of the noncondensable gas (NCG), hydrogen chloride $(\mathrm{HCl})$ and boric from the deepest to shallowest entries.. Helium and chloride isotopic composition was also determined by LBLN. This new data, along with more that is planned to be collected with the same tool, will improve our understanding of the High Temperature Zone (HTZ) at The Geysers and the source of high $\mathrm{HCl}$ and NCG levels found in certain areas thought to be associated with the HTZ.

The criteria used to pick the wells for logging and downhole sampling was:

$>$ Wells with high chloride (suggesting high temperature and a potential EGS reservoir)

$>$ Wells with deep, shallow and intermediate depth steam

$>$ Wells with low deviation angles from vertical. The closer to vertical, the higher the probability of successfully logging into the deep steam zone

The following wells were selected as potential candidates based on this criterion:

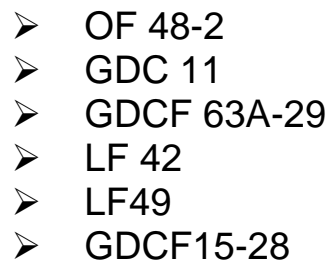

OF48-2 is the most interesting in terms of high $\mathrm{Cl}$ and deep steam. Obtaining samples from the deep steam may provide evidence as to the existence of a high temperature zone EGS reservoir below drilled depths and will allow chemical characterization of this deep, HTZ steam.

Unfortunately the dummy tool could not be run to depth in this well. 
Wells GDC 11 and GDCF 63A-29 were determined to be clear and safe to run the tools based on dummy runs. The DHS tool was deployed in these wells between February 11 and 17 at the following depths:

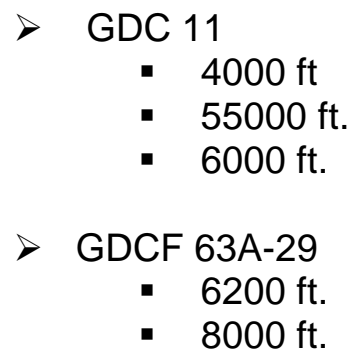

The DHS tool successfully collected samples of steam condensate and non-condensable gas at each targeted depth. The first run attempt in collecting a sample from GDC 11 resulted in no sample collection due to a high back-pressure solenoid valve that was used, given the relatively low steam pressure in the well. All subsequent runs utilized and low-pressure valve that worked effectively at each depth attempted. The raw physical data collected from the tool and during sample recovery is summarized in Appendix I. Gas samples were split with Mack Kennedy of LBLN for helium isotope analysis. The remaining NCG was analyzed by ThermoChem for routine gas analysis. The condensate samples were also split with LBLN for chloride isotope chemistry and the remainder analyzed by ThermoChem for chloride, boron, sodium and $\mathrm{pH}$. The analytical reports from ThermoChem are in Appendix II of this report. Tool specifications and photos are given in Appendix III.

\section{Further Work}

The DHS tool was deployed in the Philippines at the Chevron geothermal project in Mak-Ban during March 2009. A total of 9 runs were successfully completed in 4 wells under two-phase well-bore conditions using the high-pressure valve (wellbore pressures to $800 \mathrm{psig}$ ). The tool success rate per attempt in collecting samples was $100 \%$.

Funding is being requested under FOA DE-PS36-09G099018, topic 3, in order to increase the temperature range of the tool to $374{ }^{\circ} \mathrm{C}$, increase the pressure range of the sample valve and chambers to 5000 psig, improve the temperature resolution for sample enthalpy measurement, and add additional capabilities such as dual sample collection (2 depths per run), E-line capability and downhole two-phase mass flow and enthalpy measurement using a downhole tracer deployment module ("downhole TFT"). 
Final Report

June 29, 2009

DE-FC07-02ID14405; Amendment No. M006

\section{Physical Tool Data}




\begin{tabular}{|c|c|c|c|c|c|}
\hline Well & GDC 11 & GDC 11 & GDC 11 & GDCF $63 A-29$ & GDCF 63 A-29 \\
\hline Lab ID & $13880-1$ & $13880-2$ & $13880-3$ & $13880-4$ & $13880-5$ \\
\hline Date & $2 / 11 / 2009$ & $2 / 12 / 2009$ & $2 / 12 / 2009$ & $2 / 17 / 2009$ & $2 / 17 / 2009$ \\
\hline Depth, ft. & 6000 & 5500 & 4000 & 8000 & 6200 \\
\hline Run & 1 & 2 & 3 & 1 & 2 \\
\hline Valve Delay, min. & 165 & 145 & 60 & 165 & 60 \\
\hline Clock Time Open & $12: 25$ & $9: 45$ & $13: 30$ & $10: 35$ & $14: 25$ \\
\hline Valve Open, $\min$. & 20 & 30 & 30 & 20 & 20 \\
\hline Eutectic 1 Max, C & 155.0 & 152.4 & - & 152.4 & 151.4 \\
\hline Eutectic 2 Max, C & 156.0 & 154.0 & - & 152.6 & 152.0 \\
\hline Eutectic 3 Max, C & 156.0 & 154.0 & - & 152.4 & 152.0 \\
\hline Sample Max, C & 66.0 & 68.2 & - & 42.8 & 60.5 \\
\hline External Max, C & 237.4 & 234.9 & - & 249.0 & 238.0 \\
\hline Check Valve, psig & 10 & 25 & 25 & 25 & 25 \\
\hline Valve Type & SM 2W13X-0 104-00 & SM 2W13X-0104-00 & SM 2W13X-0 104-00 & SM 2 W13X-0104-00 & SM 2W13X-0104-00 \\
\hline Sample Pressure, psia & 41.06 & 39.31 & 30.00 & 35.2 & 31.4 \\
\hline Sample P Temp, C & 20 & 20 & 20 & 20 & 20 \\
\hline Chamber Tare, $\mathbf{g}$ & 1379.06 & 1394.08 & 1395.80 & 1400.22 & 1390.61 \\
\hline Chamber Final, $\mathbf{g}$ & 1727.99 & 1745.65 & 1689.96 & 1720.08 & 1669.86 \\
\hline Sample Net, g & 348.93 & 351.57 & 294.16 & 319.86 & 279.25 \\
\hline Sample Dilution Factor & 1.086 & 1.114 & 1.136 & 1.125 & 1.143 \\
\hline Chamber ID No. & Tl-02 & TI-05 & TI-04 & TI-06 & TI-01 \\
\hline Chamber Vol., ml & 564.70 & 565.70 & 566.00 & 564.90 & 563.40 \\
\hline Chamber HS Vol. $1, \mathrm{ml}$ & 215.77 & 214.13 & 271.84 & 245.04 & 284.15 \\
\hline Purge Gas & UHP N2 & UHP N2 & UHP N2 & UHP N2 & UHP N2 \\
\hline Initial P, psig & 0 & 0 & 0 & 0 & 0 \\
\hline Dead Vol., ml & 30 & 30 & 30 & 30 & 30 \\
\hline Add'I Flush Vol., mI & 0 & 10 & 10 & 10 & 10 \\
\hline Gas Split P, psia & 36.05 & 33.54 & 26.98 & 30.88 & 28.09 \\
\hline Gas Split T, C & 25 & 25 & 25 & 25 & 25 \\
\hline Gas Split Total Vol, mls & 35.15 & 35.15 & 35.15 & 35.15 & 35.15 \\
\hline Gas Split Chamber No. & ST-01 & ST-02 & ST-03 & ST-04 & ST-05 \\
\hline Total Gas Vol. at Split, mI & 250.92 & 249.28 & 306.99 & 280.19 & 319.30 \\
\hline Total Moles HS Gas & $2.51 \mathrm{E}-02$ & $2.32 \mathrm{E}-02$ & 2.30E-02 & $2.40 \mathrm{E}-02$ & 2.49E-02 \\
\hline Total Condensate, $\mathbf{g}$ & 302.24 & 323.11 & 319.17 & 311.82 & 308.63 \\
\hline
\end{tabular}


Final Report

June 29, 2009

DE-FC07-02ID14405; Amendment No. M006

\title{
Appendix II
}

\author{
Lab Analysis Data
}


Final Report

June 29, 2009

DE-FC07-02ID14405; Amendment No. M006

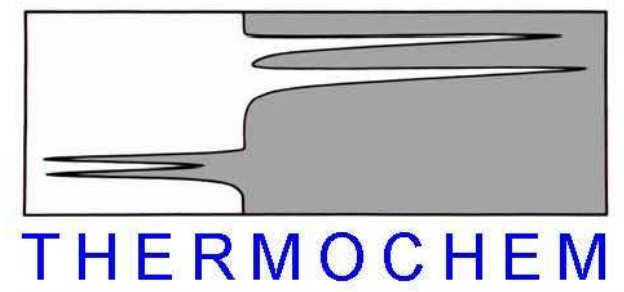

13880(1-5) March 18, 2009

Calpine

Geysers

\section{Report of Analysis}

$\begin{array}{ll}\text { Lab Number: } & 13880-1 \\ \text { Descriptor: } & \text { GDC11 2-11-09 12:25 } \\ & \text { DHS Run 1, 6000 ft. } \\ & \frac{\text { Analyte }}{\text { Sodium }} \\ & \text { Boron } \\ & \text { Chloride } \\ & \text { Lab pH (units) }\end{array}$

20.9

6.16 
Final Report

June 29, 2009

DE-FC07-02ID14405; Amendment No. M006

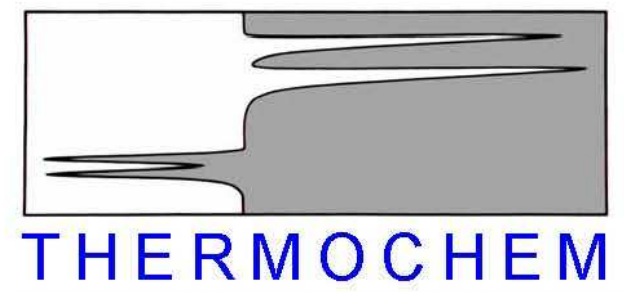

13880(1-5) March 18, 2009

Calpine

Geysers

\section{Report of Analysis}

Lab Number:

Descriptor:
$13880-2$

GDC11 2-12-09 09:45

DHS Run 2, $5500 \mathrm{ft}$.

\begin{tabular}{lc} 
Analyte & $\mathrm{mq} / \mathrm{kq}$ \\
\hline Sodium & 0.164 \\
Boron & 73.8 \\
Chloride & 12.6 \\
Lab pH (units) & 6.38
\end{tabular}


Final Report

June 29, 2009

DE-FC07-02ID14405; Amendment No. M006

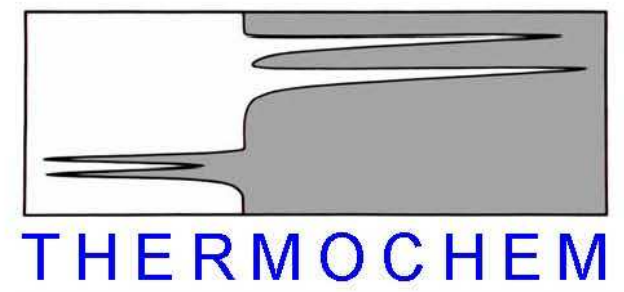

13880(1-5) March 18, 2009

Calpine

Geysers

\section{Report of Analysis}

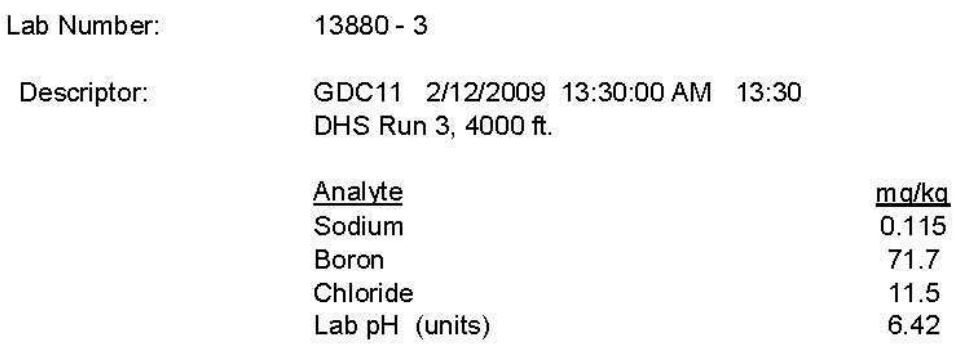


Final Report

June 29, 2009

DE-FC07-02ID14405; Amendment No. M006

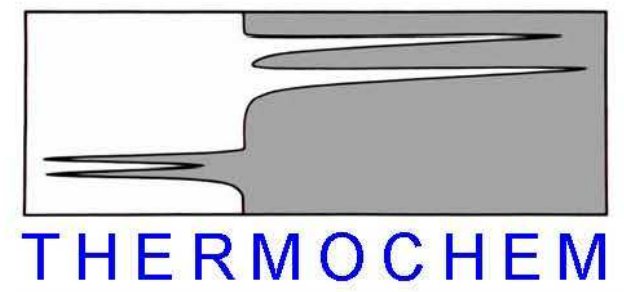

13880(1-5) March 18, 2009

Calpine

Geysers

\section{Report of Analysis}

\begin{tabular}{|c|c|c|}
\hline Lab Number: & $13880-4$ & \\
\hline \multirow[t]{6}{*}{ Descriptor: } & $\begin{array}{l}\text { GDCF } 63 A 29 \quad 2-17-09 \quad 10: 35 \\
\text { DHS Run } 1,8000 \mathrm{ft} .\end{array}$ & \\
\hline & Analyte & $\mathrm{ma} / \mathrm{kg}$ \\
\hline & Sodium & 0.063 \\
\hline & Boron & 106 \\
\hline & Chloride & 8.53 \\
\hline & Lab pH (units) & 6.19 \\
\hline
\end{tabular}


Final Report

June 29, 2009

DE-FC07-02ID14405; Amendment No. M006

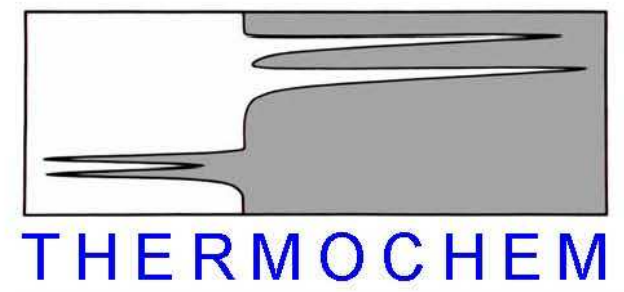

13880(1-5) March 18, 2009

Calpine

Geysers

\section{Report of Analysis}

\begin{tabular}{|c|c|c|}
\hline Lab Number: & $13880-5$ & \\
\hline \multirow[t]{6}{*}{ Descriptor: } & $\begin{array}{l}\text { GDCF } 63 \text { A29 } 2-17-09 \quad 14: 25 \\
\text { DHS Run } 2,6200 \mathrm{ft} .\end{array}$ & \\
\hline & Analyte & $\mathrm{ma} / \mathrm{kg}$ \\
\hline & Sodium & 0.133 \\
\hline & Boron & 99.5 \\
\hline & Chloride & 9.04 \\
\hline & Lab pH (units) & 6.06 \\
\hline
\end{tabular}




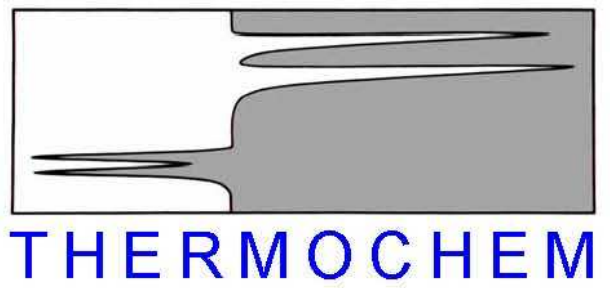

Descriptor:

GDC 11 2-11-09 12:25

Depth, ft. 6000

Lab Number: $\quad$ 13880-1

Sample Gas/Steam Ratio (moles $/ 10^{\circ}$ moles $\mathrm{H}_{2} \mathrm{O}$ ): $\quad 386$

Sample Gas/Steam Ratio (ppm by Weight):

STP mls of Air 'in Sample:

Total Weight of Condensate (grams):

None Detected

349

\begin{tabular}{l}
\multicolumn{1}{c}{ Gas } \\
\hline Water Vapor \\
Carbon Dioxide \\
Hydrogen Sulfide \\
Ammonia \\
Methane \\
Hydrogen
\end{tabular}

1. Air content based on Oxygen determination 


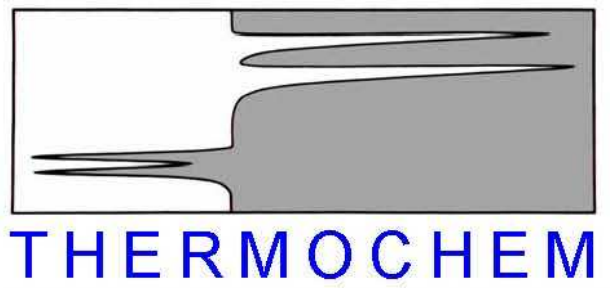

Descriptor:

GDC 11 2-12-09 09:45

Depth, ft. 5500

Lab Number: $\quad$ 13880-2

Sample Gas/Steam Ratio (moles $/ 10^{6}$ moles $\mathrm{H}_{2} \mathrm{O}$ ): $\quad 300$

Sample Gas/Steam Ratio (ppm by Weight):

STP mls of Air ${ }^{1}$ in Sample:

531

Total Weight of Condensate (grams):

None Detected

352

\begin{tabular}{l}
\multicolumn{1}{c}{ Gas } \\
\hline Water Vapor \\
Carbon Dioxide \\
Hydrogen Sulfide \\
Ammonia \\
Methane \\
Hydrogen
\end{tabular}

1. Air content based on Oxygen determination 


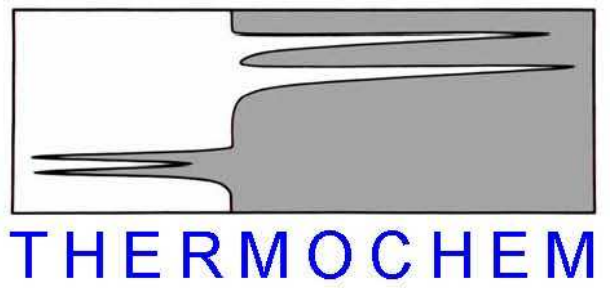

Descriptor:

GDC 11 2-12-09 13:30

Depth, ft. 4000

Lab Number: $\quad 13880-3$

Sample Gas/Steam Ratio (moles $/ 10^{\circ}$ moles $\mathrm{H}_{2} \mathrm{O}$ ): $\quad 289$

Sample Gas/Steam Ratio (ppm by Weight):

STP mls of Air ${ }^{1}$ in Sample:

Total Weight of Condensate (grams):

502

None Detected

294

$\%$ by Volume

\begin{tabular}{l}
\multicolumn{1}{c}{ Gas } \\
\hline Water Vapor \\
Carbon Dioxide \\
Hydrogen Sulfide \\
Ammonia \\
Methane \\
Hydrogen
\end{tabular}

1. Air content based on Oxygen determination
Dry Gas

$\begin{array}{ccc}N / A & N / A & 9.99 E+05 \\ 5.80 E+01 & 1.68 E+02 & 4.10 E+02 \\ 4.60 E+00 & 1.33 E+01 & 2.51 E+01 \\ 8.58 E+00 & 2.48 E+01 & 2.34 E+01 \\ 1.54 E+01 & 4.45 E+01 & 3.96 E+01 \\ 1.34 E+01 & 3.87 E+01 & 4.33 E+00\end{array}$

Moles per $10^{6} \quad$ Parts per Million Moles Water by Weight 


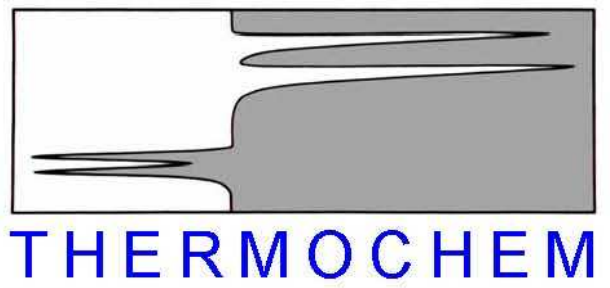

Descriptor:

GDCF 63A-29 2-17-09 10:35

Depth, ft. 8000

Lab Number: $\quad 13880-4$

Sample Gas/Steam Ratio (moles $/ 10^{6}$ moles $\mathrm{H}_{2} \mathrm{O}$ ): $\quad 186$

Sample Gas/Steam Ratio (ppm by Weight):

STP mls of Air in Sample:

Total Weight of Condensate (grams):

None Detected

320

\begin{tabular}{l}
\multicolumn{1}{c}{ Gas } \\
\hline Water Vapor \\
Carbon Dioxide \\
Hydrogen Sulfide \\
Ammonia \\
Methane \\
Hydrogen
\end{tabular}

1. Air content based on Oxygen determination 


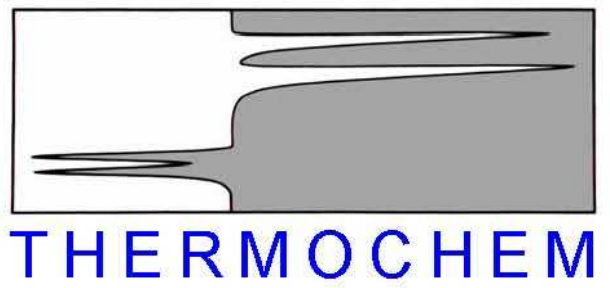

Descriptor:

GDCF 63A-29 2-17-09 14:25

Depth, ft. 6200

Lab Number: $\quad 13880-5$

Sample Gas/Steam Ratio (moles $/ 10^{6}$ moles $\mathrm{H}_{2} \mathrm{O}$ ): $\quad 175$

Sample Gas/Steam Ratio (ppm by Weight):

STP mls of Air in Sample:

Total Weight of Condensate (grams):

None Detected

279

\begin{tabular}{l}
\multicolumn{1}{c}{ Gas } \\
\hline Water Vapor \\
Carbon Dioxide \\
Hydrogen Sulfide \\
Ammonia \\
Methane \\
Hydrogen
\end{tabular}

1. Air content based on Oxygen determination 
Final Report

June 29, 2009

DE-FC07-02ID14405; Amendment No. M006

\author{
Appendix III \\ DHS Tool \\ Photo, Diagrams, Specifications
}


Final Report

June 29, 2009

DE-FC07-02ID14405; Amendment No. M006

Thermochem DHS Tool

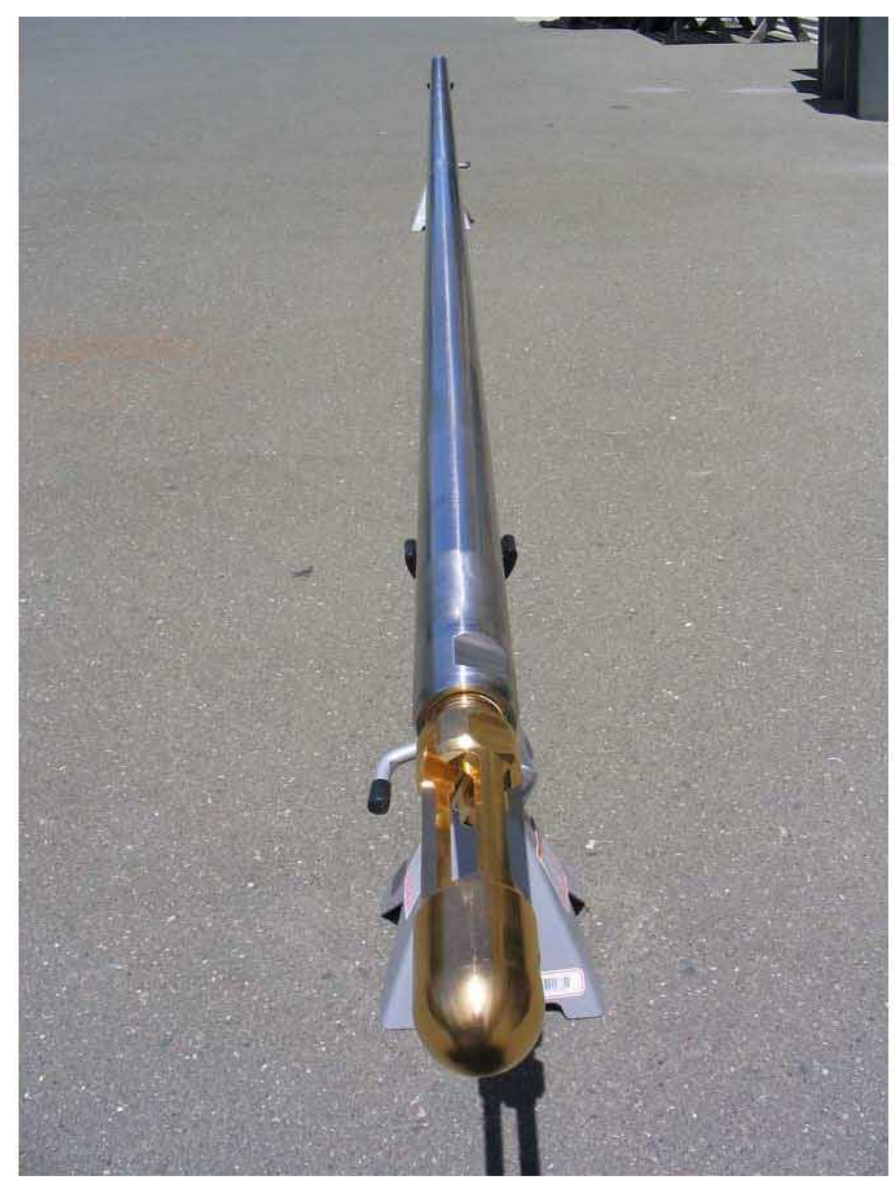




\section{Thermochem DHS Tool}

Internal Components

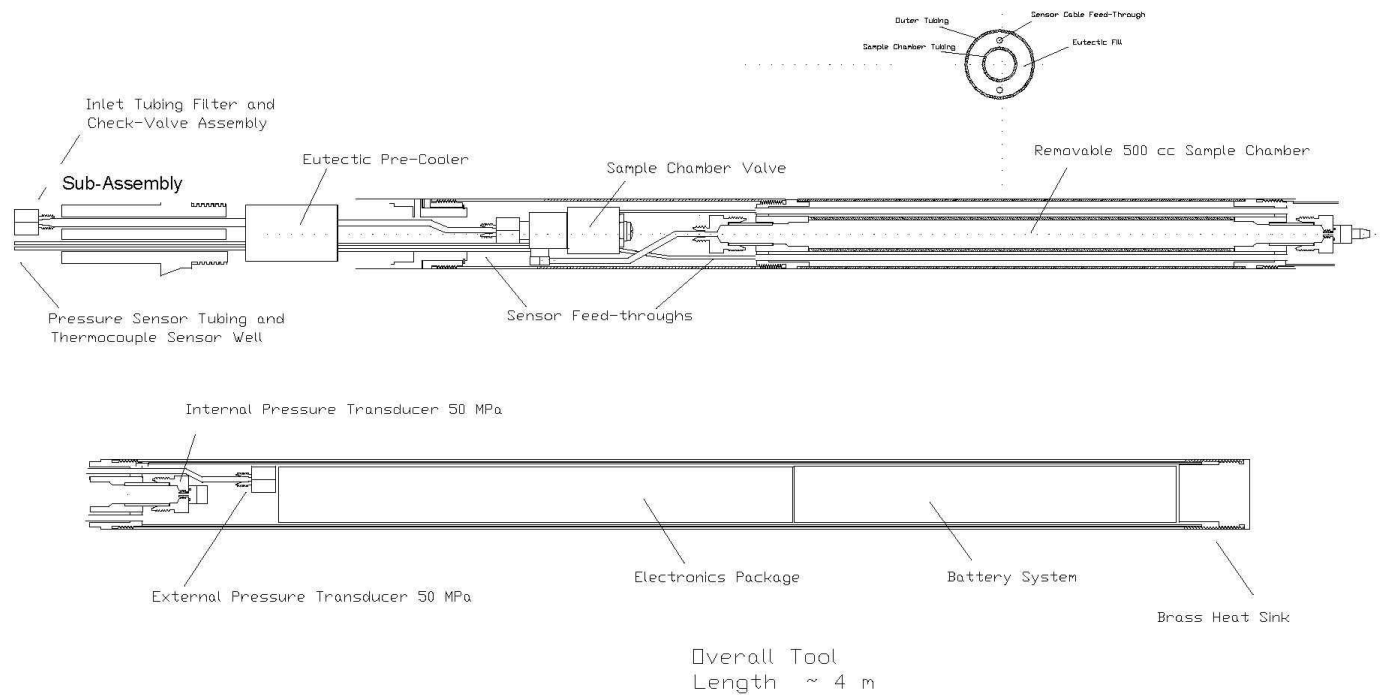


Thermochem DHS Tool

Heat Shield Over-all Dimensions

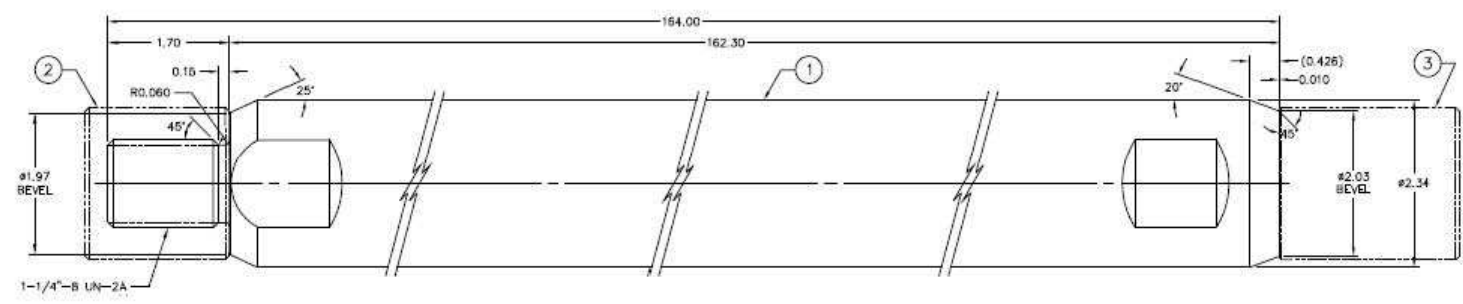

1. Heat Shield outside diameter is 2.34 inches

2. Heat Shield overall length is 164 inches (add 7.5 inches for sub-assembly)

3. Total weight of tool is $\sim 120$ pounds

4. Male 1-1/4" UN-2A thread connection to wire line cable adaptor 

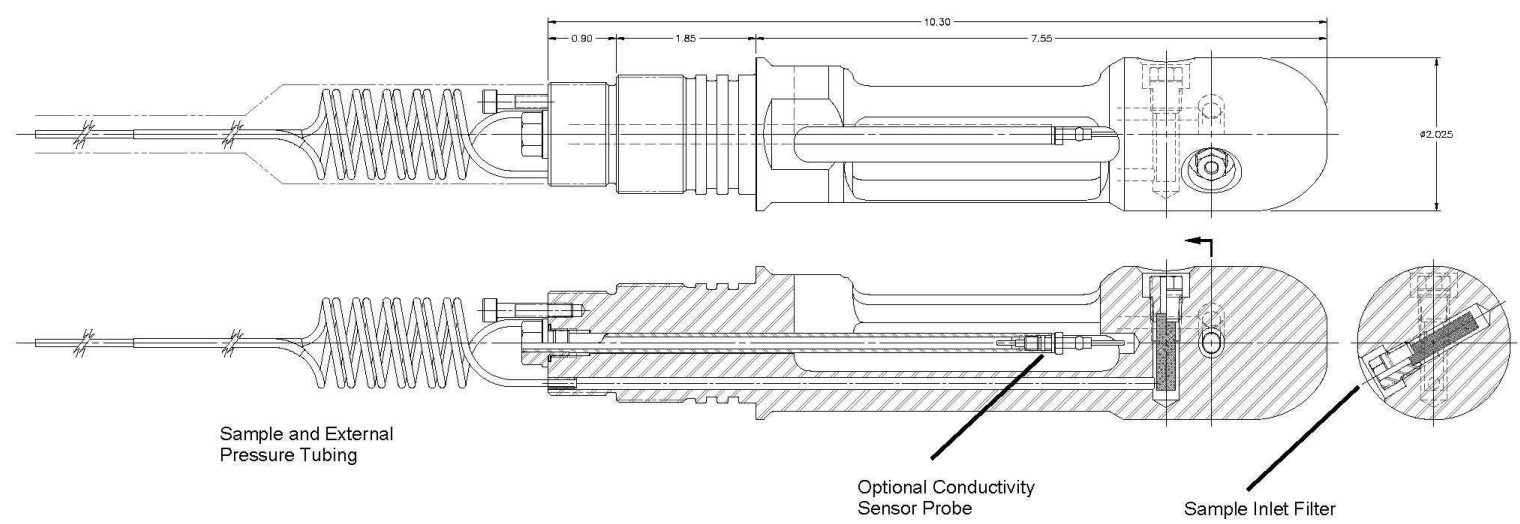
DHS Tool General Specifications

\begin{tabular}{|c|c|}
\hline Item & Specification \\
\hline Total Length & $4.35 \mathrm{~m}$ \\
\hline Tool Diameter & $59.5 \mathrm{~mm}$ \\
\hline Tool Weight & $\sim 40 \mathrm{~kg}$ \\
\hline Sample volume & $500 \mathrm{ml}$ \\
\hline Temperature & $350 \mathrm{C}$ (3 hrs or longer) \\
\hline Housing Pressure & $72 \mathrm{MPa}$ \\
\hline $\begin{array}{l}\text { Sampling } \\
\text { Mechanism }\end{array}$ & $\begin{array}{l}\text { Electrically actuated valve, } \\
\text { microprocessor timer }\end{array}$ \\
\hline Additional Features & $\begin{array}{l}\text { 1) Internal sample calorimeter } \\
\text { 2) Internal sample pressure and } \\
\text { temperature measured }\end{array}$ \\
\hline Options & $\begin{array}{l}\text { 1) External pressure and } \\
\text { temperature logging } \\
\text { 2) External conductivity logging }\end{array}$ \\
\hline
\end{tabular}


Final Report

June 29, 2009

DE-FC07-02ID14405; Amendment No. M006

Addendum to Appendix 3

Down Hole Sampling at GDC11

\section{Introduction}

On 2/11/09 the down hole sampler was run in GDC11 to test the functionality of the sampler under Geysers reservoir conditions (i.e. superheated steam in a vapor dominated reservoir) and to obtain samples from various depths. A further objective of the down hole sampling was to determine how the steam chemistry varies with depth. Samples were taken at 4000, 5500 and 6000 feet. These sample depths were chosen by analysis of a pressure-temperature-spinner (PTS) log run on $2 / 3 / 09$. The plan was to obtain samples from deep and intermediate zones of the reservoir. The data show that the deep steam entry in GDC11 produces steam which is higher in NCG concentration and in chloride.

\section{PTS Log}

The results of the P-T-S log run on 2/3/09 are summarized in Figure 1. The deepest sample depth chosen was 6000'. This is above the deepest steam entry (120 psi) at 6437' and is between it and the next higher entry at 5774' (30 psi). As shown on the graph, the approximately $4600 \mathrm{rpm}$ at that depth represents about $36 \%$ of the flow of the well. The spinner "stairsteps" up at the steam entry found at 5774'. The sample depth of 5500' corresponds to about $50 \%$ of the total well flow. The next step increase in spinner results from two entries near 4500'. The sample at 4000 ' therefore represents about $59 \%$ of the total flow of the well.

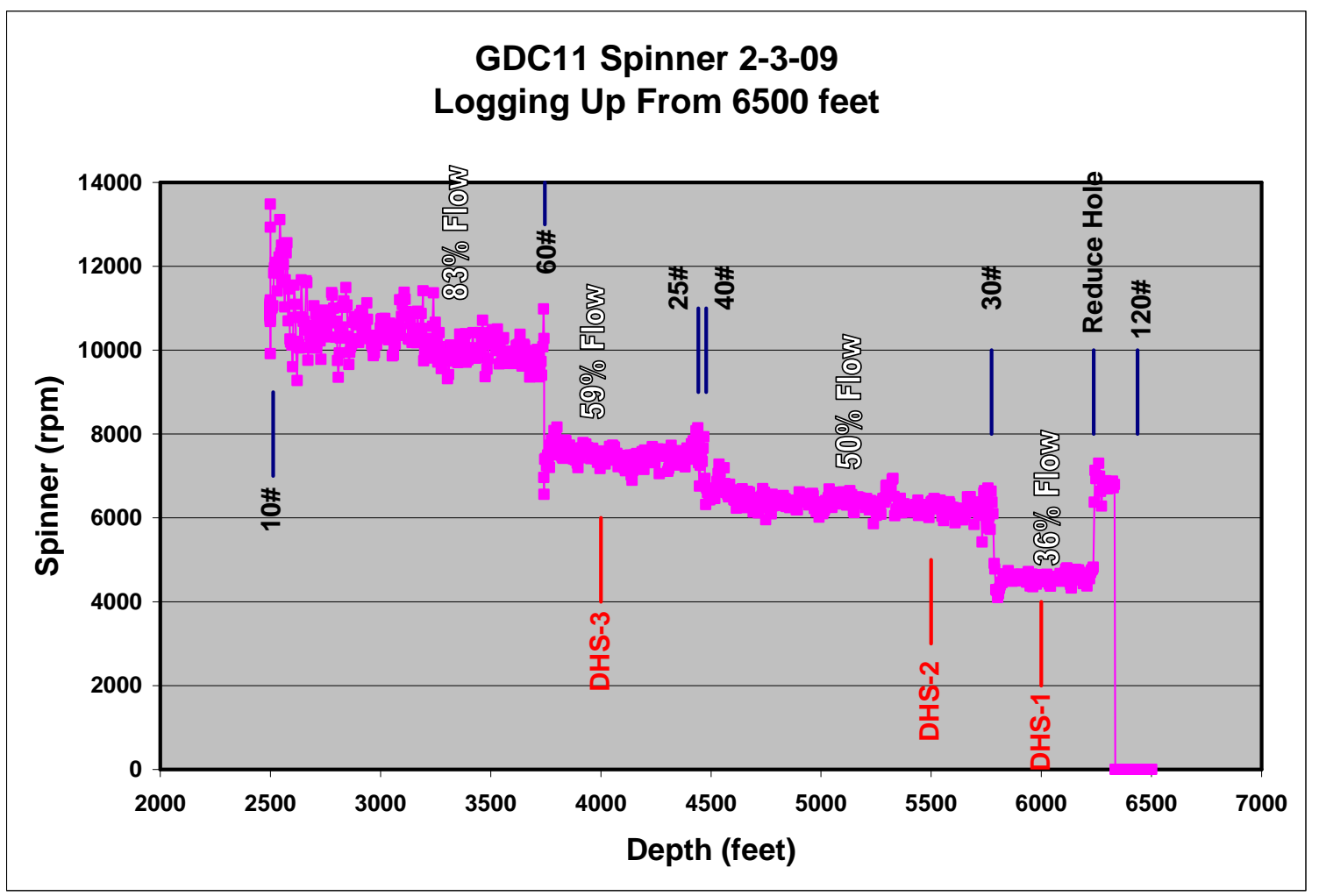


Final Report

June 29, 2009

DE-FC07-02ID14405; Amendment No. M006

\section{Variation in Steam Chemistry With Depth}

Steam chemistry data is shown in Table 1, below.

Table 1

\begin{tabular}{|c|c|c|c|c|c|c|c|c|c|c|c|c|c|c|}
\hline $\begin{array}{l}\text { Depth } \\
\text { (Feet) }\end{array}$ & $\mathrm{mpmm}$ & ppmw & $\begin{array}{c}\mathrm{CO2} \\
\text { mole frac }\end{array}$ & \begin{tabular}{|c} 
H2S \\
mole frac
\end{tabular} & \begin{tabular}{|c|}
$\mathrm{NH3}$ \\
mole frac
\end{tabular} & $\begin{array}{c}\mathrm{CH} 4 \\
\text { mole frac }\end{array}$ & $\begin{array}{c}\mathrm{H} 2 \\
\text { mole frac }\end{array}$ & Flow Frac. & $\mathrm{Na}$ & $\bar{B}$ & Cl total & $\mathrm{Cl}(\mathrm{H})$ & $\mathrm{pH}$ & $\begin{array}{c}\text { gms } \\
\text { condensate }\end{array}$ \\
\hline 4000 & 289 & 502 & 0.58 & 0.046 & 0.0858 & 0.154 & 0.134 & 0.59 & 0.12 & 71.7 & 11.5 & 11.32 & 6.42 & 294 \\
\hline 5500 & 300 & 531 & 0.592 & 0.05 & 0.0823 & 0.158 & 0.117 & 0.5 & 0.16 & 73.8 & 12.6 & 12.35 & 6.38 & 352 \\
\hline 6000 & 386 & 687 & 0.592 & 0.0583 & 0.0726 & 0.162 & 0.115 & 0.36 & 3.46 & 83.1 & 20.9 & 15.57 & 6.16 & 349 \\
\hline
\end{tabular}

From the data it is clear that NCG concentrations and chloride concentrations increase with depth of the sample (all solutes are in $\mathrm{mg} / \mathrm{kg}$ ). It is also apparent that the mixture of gases in the NCG is nearly constant with depth. Carbon dioxide constitutes $58-59 \%$ by volume of all $\mathrm{NCG}$ samples. $\mathrm{H}_{2} \mathrm{~S}, \mathrm{CH}_{4}, \mathrm{NH} 3$ and $\mathrm{H}_{2}$ all occupy similarly narrow ranges of per cent by volume.

The chloride concentration of the deepest (6000') sample is partially balanced by sodium $(3.46 \mathrm{mg} / \mathrm{kg})$. In order to determine the concentration of chloride originating as hydrogen chloride gas, an equivalent weight of $3.46 \mathrm{mg} / \mathrm{kg}$ of sodium was subtracted from the total chloride. This reduced the chloride concentration from 20.9 to $15.57 \mathrm{mg} / \mathrm{kg}$. Making minor corrections for $\mathrm{Na}$ in the shallower samples and using the flow fraction from the steam entries, the concentrations of chloride originating as $\mathrm{HCl}$ gas from each steam entry was calculated and is shown in Table 2 (right hand column).

Table 2

\begin{tabular}{|c|c|c|c|c|c|c|c|c|c|}
\hline $\begin{array}{l}\text { Sample } \\
\text { Depth }\end{array}$ & $\begin{array}{c}\mathrm{Na} \\
\mathrm{mg} / \mathrm{kg}\end{array}$ & $\begin{array}{c}B \\
\mathrm{mg} / \mathrm{kg}\end{array}$ & \begin{tabular}{|l} 
Cl Total \\
$\mathrm{mg} / \mathrm{kg}$
\end{tabular} & $\mathrm{pH}$ & $\begin{array}{c}\text { Total Cl(H) } \\
\mathrm{mg} / \mathrm{kg}\end{array}$ & $\begin{array}{c}\text { Steam Entry Depth } \\
\text { (feet) }\end{array}$ & $\begin{array}{c}\text { Flow } \\
\text { Fraction }\end{array}$ & Cumflow \% & $\begin{array}{c}\text { Steam Entry } \mathrm{Cl}(\mathrm{H}) \\
\mathrm{mg} / \mathrm{kg}\end{array}$ \\
\hline & & & & & & 2610 & 0.17 & & \\
\hline & & & & & & 3293 & 0.05 & & \\
\hline & & & & & & 3773 & 0.19 & & \\
\hline \multirow[t]{2}{*}{4000} & 0.115 & 71.7 & 11.5 & 6.42 & 11.32 & & & 59 & \\
\hline & & & & & & 4470 & 0.09 & & 5.6 \\
\hline \multirow[t]{2}{*}{5500} & 0.164 & 73.8 & 12.6 & 6.38 & 12.35 & & & 50 & \\
\hline & & & & & & 5800 & 0.14 & & 4.11 \\
\hline \multirow[t]{2}{*}{6000} & 3.46 & 83.1 & 20.9 & 6.16 & 15.57 & & & 36 & \\
\hline & & & & & & 6310 & 0.36 & & 15.57 \\
\hline
\end{tabular}

The variations in steam chemistry as a function of depth are shown in Figure 1. NCG and solute concentrations ( $\mathrm{Cl}$ and $\mathrm{B}$ ) all show similar trends, with a sharp increase in concentrations corresponding to the deep sample. The bottom trend on the graph is the calculated chloride (from $\mathrm{HCl}$ ) for each steam entry. Consequently, the depths are not coincident with the sample depths. 
Final Report

June 29, 2009

DE-FC07-02ID14405; Amendment No. M006

\section{Conclusion}

High chloride concentrations in Geysers steam results from deep steam entries to wells. Previous down hole sampling at DX42 with a prototype of the current down hole sampler showed a similar trend of increasing chloride with depth. This may be indicative of NCG originating from magmatic sources.

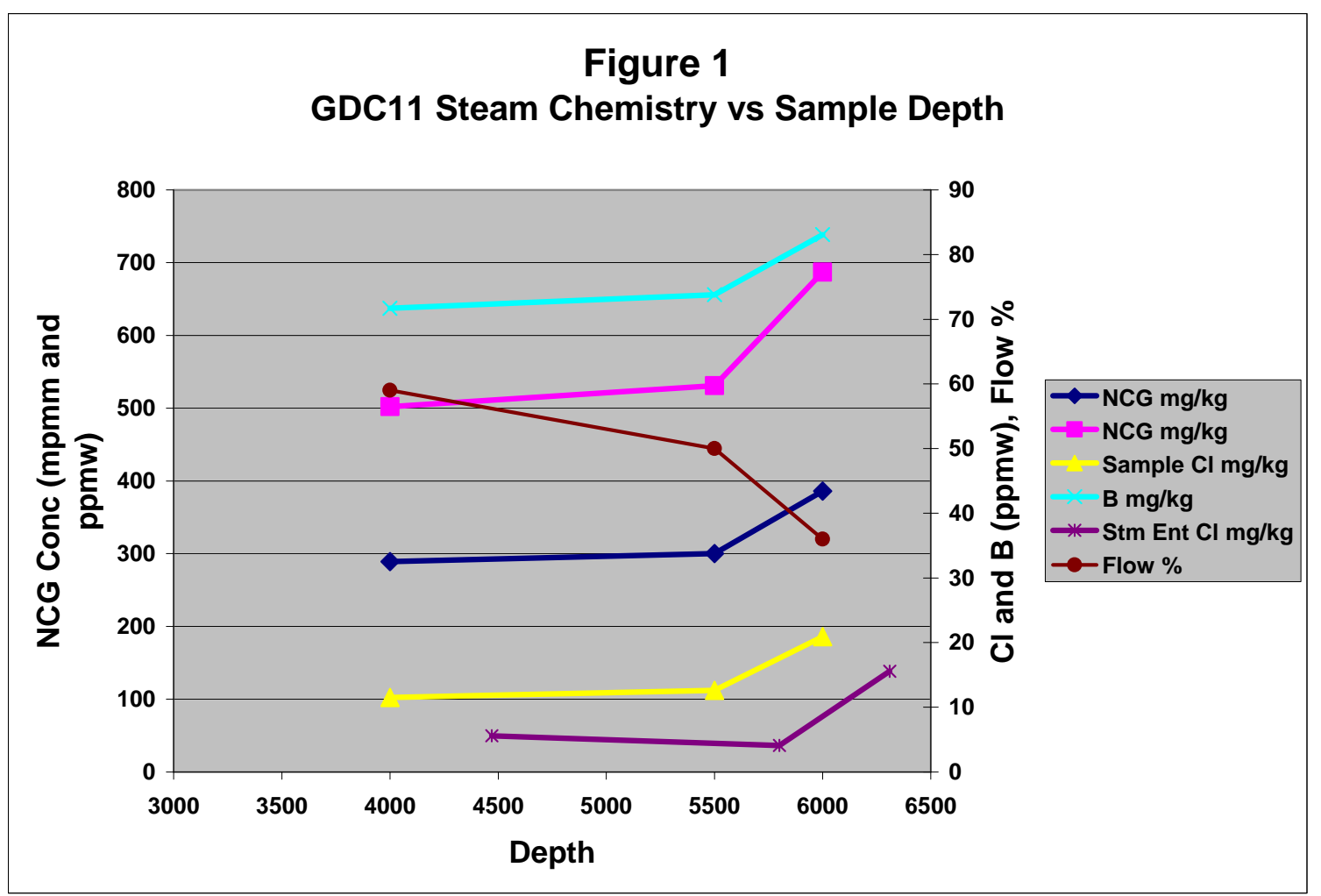

